\title{
Trading Frequency and Asset Pricing on the London Stock Exchange: Evidence from a New Price Impact Ratio
}

\author{
Chrisostomos Florackis ${ }^{\mathrm{a}}$, Andros Gregoriou ${ }^{\mathrm{b}}$, and Alexandros Kostakis ${ }^{\mathrm{c}}$
}

\begin{abstract}
In this study we propose a new price impact ratio as an alternative to the widely used Amihud's (2002) Return-to-Volume ratio (RtoV). This new measure, which is deemed Return-to-Turnover ratio (RtoTR), essentially modifies Rto V by substituting trading volume in its denominator with the turnover ratio for each security. We demonstrate that the new price impact ratio has a number of appealing features. Using daily data from all stocks listed on the London Stock Exchange over the period 1991-2008, we provide overwhelming evidence that this ratio, while being unequivocal to construct and interpret, is also free of a size bias. More importantly, it encapsulates the stocks' cross-sectional variability in trading frequency, a relatively neglected but possibly important determinant of stock returns given the recently observed trends in financial markets. Overall, our findings argue against the conventional wisdom that there is a simple direct link between trading costs and stock prices by strongly suggesting that it is the compound effect of trading frequency and transaction costs that matters for asset pricing, not each aspect in isolation.
\end{abstract}

JEL classification: G10; G12; G14

Keywords: Trading Frequency; Transaction Costs; Price Impact Ratio; Asset Pricing;

Illiquidity

${ }^{a}$ Corresponding author. The Management School, University of Liverpool, Chatham Street, L69 7ZH, Liverpool, United Kingdom. Tel.: + 44 (0) 151 7953807. Fax: +44 (0) 151 7953000, E-mail: C.Florackis@liv.ac.uk.

${ }^{\mathrm{b}}$ Norwich Business School, University of East Anglia, United Kingdom, Tel: +44 (0) 160 359132, E-mail: a.gregoriou@uea.ac.uk.

${ }^{c}$ Department of Economics, University of Glasgow, United Kingdom, Tel: +44 (0) 141 3305065, E-mail: a.kostakis@1bss.gla.ac.uk. 


\title{
Trading Frequency and Asset Pricing on the London Stock Exchange: Evidence from a New Price Impact Ratio
}

\begin{abstract}
In this study we propose a new price impact ratio as an alternative to the widely used Amihud's (2002) Return-to-Volume ratio (RtoV). This new measure, which is deemed Return-to-Turnover ratio (RtoTR), essentially modifies RtoV by substituting trading volume in its denominator with the turnover ratio for each security. We demonstrate that the new price impact ratio has a number of appealing features. Using daily data from all stocks listed on the London Stock Exchange over the period 1991-2008, we provide overwhelming evidence that this ratio, while being unequivocal to construct and interpret, is also free of a size bias. More importantly, it encapsulates the stocks' cross-sectional variability in trading frequency, a relatively neglected but possibly important determinant of stock returns given the recently observed trends in financial markets. Overall, our findings argue against the conventional wisdom that there is a simple direct link between trading costs and stock prices by strongly suggesting that it is the compound effect of trading frequency and transaction costs that matters for asset pricing, not each aspect in isolation.
\end{abstract}

JEL classification: G10; G12; G14

Keywords: Trading Frequency; Transaction Costs; Price Impact Ratio; Asset Pricing;

Illiquidity 


\section{Introduction}

As recent events in financial markets have demonstrated, illiquidity appears to be one of the most important market frictions that influence asset prices. Despite the considerable attention that this issue has attracted during the past two decades, it remains an elusive concept (Amihud (2002), Pastor and Stambaugh (2003)). ${ }^{1}$ This has led to the emergence of a vast literature proposing a series of measures for particular aspects of illiquidity (e.g. trading costs, trading quantity, trading speed and price impact). These measures include the bid-ask spread (Amihud and Mendelson (1986a)), relative spread (Amihud and Mendelson (1986b), Loderer and Roth (2005)), effective spread (Lee (1993), Heflin and Shaw (2000)), amortized spread (Chalmers and Kadlec (1998)), Kyle's lambda (Kyle (1985), Brennan and Subrahmanyam (1996)), trading volume (Brennan, Chordia and Subrahmanyam (1998)), turnover rate (Datar, Naik and Radcliffe (1998), Chordia, Subrahmanyam, Anshuman (2001)), number of zeroreturn days (Bekaert, Harvey and Lundblad (2005)) and price sensitivity to order flow (Pastor and Stambaugh (2003)). ${ }^{2}$

The most commonly used measure in the recent empirical literature is the price impact ratio of Amihud (2002), which is defined as the average monthly ratio of daily absolute returns to daily trading volume in monetary terms (henceforth, RtoV) (see e.g. Acharya and Pedersen (2005), Korajczyk and Sadka (2008), Goyenko and Ukhov (2009)). This measure is appealing because it is easy to compute for long time periods given the wide availability of returns and trading volume data. In addition, it is intuitively attractive because the average

\footnotetext{
${ }^{1}$ For example, the seminal theoretical studies of Constantinides (1986), Heaton and Lucas (1996) and Vayanos (1998) address the impact of transaction costs on asset prices. Jacoby, Fowler and Gottesman (2000) develop a liquidity adjusted CAPM, where systematic and liquidity risk are inseparable, and find that the true measure of systematic risk when considering liquidity costs is based on net (after bid-ask spread) returns. More recently, Lo, Mamaysky and Wang (2004) propose a dynamic equilibrium model of asset prices and trading volume where agents face fixed transaction costs. They show that even small fixed costs can give rise to large "no-trade" regions for each agent's optimal trading policy. Liu (2004) re-affirms the findings of Lo et al. (2004) in the presence multiple risky assets. On the empirical side, research in asset pricing has shown that liquidity risk generates substantial higher cost of capital for the least liquid stocks (see Amihud, 2002, Pastor and Stambaugh (2003), Acharya and Pedersen (2005) among others).

${ }^{2} \mathrm{O}$ ' Hara (2003) and Amihud, Medelson and Pedersen (2005) provide a comprehensive review of the literature on illiquidity and asset pricing.
} 
daily price response associated with a dollar of trading volume renders it a good proxy for the theoretically founded Kyle's price impact coefficient (Hasbrouck (2005), and Goyenko, Holden and Trzcinka (2009)).

Despite its popularity, Amihud's price impact ratio is not free of limitations. In the cross-sectional dimension, RtoV ratio builds in a size effect because trading volume in monetary terms is by construction positively correlated with market capitalization and, as a result, it is by no means comparable across stocks with different market values. This shortcoming has been firstly highlighted by Cochrane (2005a), who argues that the RtoV ratio is expected to be much higher for small capitalization stocks, forcing the conclusion that small capitalization stocks are more illiquid than big capitalization stocks. Another important limitation of RtoV is that it neglects the trading frequency dimension of liquidity; this may be inappropriate given that actual stocks' trading frequency exhibits considerable time-series as well as cross-sectional variation (Datar et al. (1998)).

This study contributes to the literature by proposing an alternative, more appropriate, price impact ratio defined as the average monthly ratio of daily absolute stock return to its turnover ratio (henceforth RtoTR), essentially replacing the trading volume of a stock with its turnover ratio in the denominator of Amihud's ratio. Given that information on turnover ratios is easily accessible in the public domain, the proposed measure inherits the simplicity and data availability that characterizes Amihud's ratio, while it is free of any size bias. This is because turnover does not necessarily exhibit an inherent size-related pattern (Brown, Crocker, Foerster (2009)). Therefore, the proposed measure is more suitable to insulate the price impact from the size effect.

More importantly, the RtoTR ratio is not just a methodological contribution. Using turnover rates to calculate price impact ratios helps control not only for the importance of trading costs but also for that of trading frequency on asset pricing. The role of trading frequency, which can be effectively approximated by turnover rate, is highlighted by the 
fundamental theoretical result of Amihud and Mendelson (1986a, p.228) stating that for a risk-neutral investor with trading intensity $\mu$, the required return on security $i$ is given by:

$$
E\left(r^{i}\right)=r^{f}+\mu \frac{C^{i}}{P^{i}}
$$

where $C^{i}$ stands for the illiquidity cost of asset $i$ and $P^{i}$ denotes its price. In other words, while it is true that higher transaction costs command higher expected returns ceteris paribus, it is also the case that expected returns increase with the asset's trading frequency. This proposition implies that even small transaction costs may lead to a high premium if they are very frequently incurred, leading to the conclusion that it is the compound effect of trading frequency and transaction costs that matters for asset pricing, not each aspect in isolation. By introducing a price impact ratio that attempts to control for such a compound effect, we extend earlier studies on the subject that have examined the two effects independently.

The particular emphasis of our price impact ratio, RtoTR, on trading frequency has another merit. Trading activity of dominant stock market participants has considerably increased through time. This is a well-known development that is manifested by the existence of institutional investors who hold substantial levels of stock and take actions characterized by short-termism and short holding horizons (Bogle (2005), French(2008)). At the same time, transaction costs have been driven down due to technological innovations and implementation of effective microstructure mechanisms in organized exchanges (Chordia, Roll and Subrahmanyam (2001), French (2008), Ben-rephael, Kadan and Wohl (2008)). As a consequence, the development of a price impact ratio that explicitly considers the impact of trading frequency on required premia is of utmost importance because stocks actually exhibit a considerable cross-sectional variability in their turnover ratios.

Using RtoTR as well as RtoV for comparison purposes, we rank stocks listed on the London Stock Exchange (LSE) and construct portfolios to examine the issue whether these price impact ratios affect the cross-section of stock returns for the period 1991-2008. Previewing our results, we find that stocks with high RtoV values lead to higher expected 
returns compared to stocks with low RtoV values. This result, which is consistent with the findings of other studies that utilize the RtoV ratio, suggests that stocks with high stock price reaction to a British pound of trading volume yield higher returns (see e.g. Amihud (2002) and Liu (2006)). Interestingly, however, we find a striking reversal of the portfolio returns' ordering once the trading-frequency adjusted price impact ratio (i.e. RtoTR) is used as a ranking criterion. Specifically, stocks with low RtoTR values are the ones that yield much higher risk-adjusted returns as compared to stocks with high RtoTR values. Put differently, stocks with very high turnover ratios, and hence very low RtoTR values, command high abnormal returns even if the price impact of this trading activity is relatively low. These findings support the view that the trading frequency effect overwhelmingly dominates the transaction cost effect in the determination of the corresponding premium, leading to the result that low RtoTR stocks outperform high RtoTR stocks.

Moreover, confirming the built-in size bias of Amihud's measure, our findings suggest that the extra returns yielded by stocks with high RtoV values relative to stocks with low RtoV values evaporate once we account for the size factor in multi-factor models. Crucially, the new price impact ratio suggested in this paper does not suffer from such a bias, since the premium that low RtoTR stocks earn is present in all multi-factor model specifications. We then construct a price impact (PI) factor via our measure to further examine whether the size and momentum anomalies can be explained through a PI-adjusted asset pricing model. The results indicate that augmenting the CAPM with the PI factor helps partly explain the momentum but not the size anomaly. Finally, this factor is also shown to be valuable for a mean-variance portfolio optimizer. These results are robust to a series of further checks.

The remainder of the paper is structured in the following way. Section 2 provides the motivation, discussing the shortcomings of the Amihud ratio and introduces the new price impact ratio, RtoTR, which controls for the trading frequency effect. Section 3 describes the data and the construction of the portfolios based on the RtoV and RtoTR measures. The empirical results in a time-series and cross-sectional framework are presented in Section 4. 
Section 5 conducts varies robustness tests of the empirical analysis in terms of momentum and size premia. Furthermore, we examine the value of the PI factor in a simple asset allocation setup. Finally, Section 6 concludes.

\section{Motivation, related literature and the new price impact ratio}

\subsection{Amihud's price impact ratio and its shortcomings}

The ratio proposed by Amihud (2002) is widely accepted as one of the most appropriate and straightforward price impact measures to construct. Formally, it is calculated by the following ratio:

$$
\operatorname{RtoV}_{i t}=\frac{1}{D_{i t}} \sum_{d=1}^{D_{i t}} \frac{\left|R_{i t d}\right|}{V_{i t d}}
$$

where $R_{i t d}$ and $V_{i t d}$ are, respectively, the return and monetary volume of stock $i$ on day $d$ at month $t$ and $D_{i t}$ is the number of valid observation days in month $t$ for stock $i$.

This ratio has several advantages compared to the traditional proxies that capture specific aspects of illiquidity. Firstly, it has a very intuitive meaning. Specifically, by directly measuring the impact of a (monetary) unit of trading volume on stock's return, it implies that the greater the response of returns, the more illiquid this stock is considered to be. While there is already a large number of existing studies arguing that trading volume is related to liquidity (e.g. Brennan et al. (1998), Chordia et al. (2001)), the contribution of this ratio is to capture the impact of trading volume on stock price movements and translate it into transaction cost (Acharya and Pedersen (2005)).

Secondly, RtoV is a good empirical proxy for the theoretically fine concept of Kyle's (1985) lambda (see Hasbrouck (2005)). This aspect of illiquidity is tangential to the order imbalance effect studied by Pastor and Stambaugh (2003). In particular, large buy/ sell orders for illiquid stocks lead to wide short-term stock price movements due to adverse selection and inventory costs that partly "bounce back" the following day as this large order shock is being 
absorbed (Amihud and Mendelson (1980), O’Hara (2003)). ${ }^{3}$ Moreover, as Cochrane (2005a) notes, Amihud's ratio also has a "price discovery" component due to the fact that trading activity may be motivated by information or expectations regarding future stock price movements (see also Daniel, Hirshleifer and Subrahmanyam (1998)). In addition, this ratio can be interpreted as a measure of disagreement among investors (Amihud (2002)). When investors agree about the implication of news, stock prices change with a low trading volume, while large stock price movements associated with excessive trading volume reveal underlying heterogeneous beliefs

It should be further noted that RtoV is closely related to the Aminvest measure, which is very popular among professional investors (Khan and Baker (1993)). Aminvest is roughly the inverse of the RtoV ratio, given by the sum of daily volume to the sum of the absolute return and it has been employed by Amihud, Mendelson and Lauterbach (1997) and Berkman and Eleswarapu (1998). To this end, RtoV has become very popular for practical issues. It is easy to calculate for long periods because volume and returns data are widely available without resorting to detailed, high quality microstructure data that are difficult to obtain for long periods. For example, the highly sophisticated PIN (probability of informed trading) measure of Easley, Hvidkjaer and O'Hara (2002) and Easley, Hvidkjaer and O' Hara (2010) requires transactions data that are hard to acquire for long time periods and for most of the international markets.

Finally, even though Amihud's ratio does not exactly measure transaction costs, it is still very useful and convenient as compared to traditional measures of transaction costs, such as the bid-ask spread (Amihud and Mendelson (1986a), Amihud and Mendelson (1991)). Bidask spreads obtained at a daily frequency may be uninformative because they are noisy and they usually refer to end-of-day transactions. As Acharya and Pedersen (2005) note, larger

\footnotetext{
${ }^{3}$ Similar is the intuition underlying the price impact measure of Brennan and Subrahmanyam (1996). In particular, they implement Kyle's model by estimating the price response to both the signed order size and the fixed cost of trading.
} 
bid-ask spreads are indicative of illiquidity but do not provide us with any information regarding the "depth" of the market and, most importantly, regarding the magnitude of price impact due to a trade. In particular, Peterson and Fialkowski (1994) show that the quoted spread is a poor proxy for actual transaction costs. Moreover, closing price bid-ask spreads may be more easily manipulated by market makers, rendering them uninformative. There is the additional problem that in some databases (e.g. Thomson Datastream), bid-ask spreads appear as symmetric around the close price for most of the stocks, making relative spreads uninformative too. ${ }^{4}$

Despite its insightfulness, Amihud's ratio does not come without its shortcomings. Focussing on the properties of this measure from a cross-sectional asset pricing perspective, two major issues arise:

i) $R t o V$ is by no means comparable across stocks with different market capitalization and, therefore, carries a significant size bias. Small cap stocks are bound to exhibit lower trading volume (in monetary terms) than big cap stocks even when they exhibit the same turnover ratio. In other words, based on the RtoV ratio, small cap stocks are automatically characterized as "illiquid" only due to their size. Cochrane (2005a, p. 5) explicitly states this bias, warning researchers that use RtoV to draw conclusions that the size premium is due to illiquidity. While this conclusion may still be generally valid, it becomes a tautology when this particular ratio is employed.

ii) RtoV neglects investors' stock holding horizons. More specifically, even though this ratio attempts to proxy the cost of transacting in a rather intuitive way, it is uninformative with respect to the frequency at which this cost is incurred. As a result, Amihud's ratio implicitly assumes that trading frequency is similar across stocks, and hence it should not affect liquidity premia. Nevertheless, as we discuss in the following subsections, trading frequency has become and dominant issue and it is expected to significantly affect asset

\footnotetext{
${ }^{4}$ Relative and effective spreads are affected by the same data-quality problems, since they are based on bid-ask prices. Chalmers and Kadlec (1998, p.163) analyze some further limitations of these spreads measures.
} 
pricing due to its considerable cross-sectional as well as time-series variation (see Datar et al. (1998)).

\subsection{A new price impact ratio}

The shortcomings of Amihud's ratio motivate us to introduce a new price impact ratio. This is formally given by the following expression:

$$
\operatorname{RtoTR}_{i t}=\frac{1}{D_{i t}} \sum_{d=1}^{D_{i t}} \frac{\left|R_{i t d}\right|}{T R_{i t d}}
$$

where $T R_{i t d}$ is the Turnover Ratio of stock $i$ at day $d$ and $D_{i t}$ and $R_{i t d}$ are as previously defined.

Comparing our measure to RtoV, we essentially replace trading volume with turnover ratio in the denominator. RtoTR has a similar intuitive interpretation showing how much stock price responds to one percent of turnover rate. The focus on $T R$, a measure of trading activity, enables comparability across assets. Therefore, the proposed measure not only inherits the conceptual advantages of Amihud's ratio, but it also introduces some additional appealing features. More specifically, the proposed measure is easy to calculate, being also comparable across different stock markets and countries, because it does not include a monetary variable and it does not require price level or exchange rate adjustments. Most importantly, it is free of any size bias because there is no mechanical reason why big capitalization stocks should exhibit by construction higher turnover ratios. This fact renders it more appropriate for crosssectional asset pricing studies and it enables us to disentangle price impact and size effects.

Crucially, our measure is not just a quick fix to overcome the size bias of Amihud's ratio. It actually has a very neat theoretical foundation, highlighting the importance of trading frequency and holding periods. To support this argument, we resort to Proposition 1 of Amihud et al. (2005, p. 281) that iterates Proposition 2 of Amihud and Mendelson (1986a). 
This proposition states that for a risk-neutral investor with trading intensity $\mu$, the required return on security $i$ is given by:

$$
E\left(r^{i}\right)=r^{f}+\mu \frac{C^{i}}{P^{i}}
$$

where $C^{i}$ stands for the illiquidity cost of asset $i$ and $P^{i}$ denotes its price. In other words, Amihud and Mendelson (1986a) state that expected excess returns depend not only on the transaction cost of the asset but also on its trading intensity, i.e. the probability according to which this cost is incurred.

The previous statement has an obvious implication; it is the combined effect of transaction costs and trading frequency that determines the required premium, not each aspect in isolation. This is also true in the model of Acharya and Pedersen (2005) that deals with the case of a risk-averse investor (see their discussion in p. 392-393). This is a crucial point because if trading frequencies, and hence turnover ratios, vary considerably across stocks, then they may well dominate transaction costs in determining the overall effect. It is surprising that this aspect of liquidity asset pricing is rarely mentioned in the literature, with the notable exception of Chalmers and Kadlec (1998). This is presumably because theoretical models have been developed within a single risky asset framework. For example, in their empirical investigation, Acharya and Pedersen (2005) assume that trading intensity, and hence turnover ratio is either fixed and exogenously given or an estimated constant that applies uniformly to the cross-section of stocks. Such an assumption is clearly invalid given the cross-sectional variation in stocks' turnover ratios (Datar et al. (1998)).

By controlling for both the trading frequency and the transaction cost effects via the proposed price impact ratio, our analysis also helps explain the mixed evidence in prior literature regarding the relationship between turnover ratios and stock returns. For example, Datar et al. (1998) and Nguyen, Mishra, Prakash and Ghosh (2007) document a negative relationship by arguing that stocks with higher turnover ratio are characterized by greater trading speed and are thought to be more liquid, dictating a lower expected return as 
compared to stocks exhibiting low turnover ratios. On the other hand, Brown et al. (2009) report that stocks with high turnover ratios exhibit higher returns. ${ }^{5}$ We argue that using RtoTR is more appropriate than solely considering trading activity measures, exactly because it is the combined effect of trading costs and frequency that matters rather than trading activity in isolation.

Finally, our ratio contributes to the literature by providing an alternative to the amortized spread of Chalmers and Kadlec (1998), which also attempts to measure the combined effect of trading frequency and transaction costs. Their empirical results provide strong evidence in favour of this combined effect in determining premia, since amortized spreads are found to be more strongly priced as compared to unamortized spreads. In particular, their analysis confirms that stocks with similar spreads exhibit vastly different turnover ratios, so the spread alone cannot be a fully informative proxy for illiquidity. The main shortcoming of Chalmers and Kadlec's (1998) measure, however, is that it requires data on bid and ask prices. As a result, it inherits the problems that we previously discussed for other spreads-based measures and refer to the quality of data and the difficulty in acquiring informative quotes at a daily frequency. ${ }^{6}$ Therefore, drawing the analogy with the usefuleness of Amihud's ratio, we argue that RtoTR could be more practical than the amortized spread for empirical purposes.

\subsection{Trends in transaction costs and trading frequency}

In addition to its theoretical foundations and methodological advantages, the suggested price impact ratio is also appealing due to the recently observed trends in trading costs and frequency. This subsection discusses these trends confirming the importance of incorporating

\footnotetext{
${ }^{5}$ Chan and Faff (2005) also report mixed evidence on the pricing of a liquidity factor using turnover ratios as proxies for liquidity in Australian stocks.

${ }^{6}$ It should be mentioned that Chalmers and Kadlec (1998) overcome this problem by utilizing high quality intraday data on bid-ask prices. Such detailed datasets are hardly available in international markets for long time series.
} 
trading frequency in a price impact ratio. In particular, French (2008) demonstrates that total trading costs paid by investors in the U.S. market have been reduced from 146 basis points in 1980 to a tiny 11 basis points in 2006. At the same time, the annual turnover ratio has risen from $20 \%$ in 1975 and $59 \%$ in 1990 to an astonishing $215 \%$ in 2007 . Similar is the case for U.K. stock market. According to the World Federation of Exchanges, the turnover ratio in the LSE has increased from $40.5 \%$ in 1995 to $152.7 \%$ in $2008 .^{7}$

A series of important developments are associated with these trends. Trading costs have been driven down due to several institutional and technological changes. For example, there is a continuous effort by organized exchanges to improve their market microstructure mechanisms in order to enhance liquidity (Biais, Glosten and Spatt (2005), O’ Hara (2007)). ${ }^{8}$ Moreover, technological innovation enabled the introduction of electronic trading systems. There is ample empirical evidence that electronic computerized trading systems improve market liquidity (Jain (2005)). Naik and Yadav (2004) find that liquidity is significantly increased for FTSE 100 stocks, which account for approximately $80 \%$ of total trading volume in the LSE, once they are traded on an electronic limit-order trading system. ${ }^{9}$ Confirming this finding, Chakravarty, Panchagesan and Wood (2005) argue that the decline in trading commissions can be attributed to the growth of alternative, automated trading systems.

The introduction of online brokerage accounts intensified the competition among brokers and other providers of trading services, driving down costs (Barber and Odean (2002)). At a macro level, there is fierce competition among international stock markets for

\footnotetext{
7 Data on share turnover are available for a series of international stock markets at http://www.worldexchanges.org/statistics/annual/equity-markets.

${ }^{8}$ For example, Venkataraman (2001) documents a trend towards automation of auction trading mechanisms. More recently, Venkataraman and Waisburd (2007) show the beneficial effects for Paris Bourse liquidity due to the introduction of designated market makers.

${ }^{9}$ Along the same lines, Barclay et al. (1999) document that liquidity has risen on the NASDAQ following the introduction of the electronic trading system. Domowitz (2002) finds for a sample of 42 countries that a screen system increases market liquidity by reducing trading costs and increasing trading volume.
} 
attracting new listings. This competition is associated with mergers of exchanges to exploit economies of scale and the emergence of cross-country trading platforms. ${ }^{10}$ Moreover, the observed proliferation of trading venues has led to the fragmentation of order flow, which in turn reduces transaction costs (O'Hara and Ye (2009)). It should be mentioned that regulatory initiatives for greater transparency (e.g., the Markets in Financial Instruments Directive in the European Union) may have also contributed to the reduction of transaction costs, given that asymmetric information is an important determinant of bid-ask spreads. Finally, another potential reason for this development is financial innovation. As Ben-Rephael et al. (2008) note, index funds, Exchange Traded Funds (ETFs) and other collective investment vehicles that offer economies of scale with respect to transaction costs, have enabled individual investors to invest indirectly in stocks that would be otherwise expensive to trade.

The second important trend is the increase in trading activity. The most obvious reason is the reduction in trading costs that we previously discussed (see also Barber and Odean (2002), Chordia, Roll and Subrahmanyam (2009)). Moreover, it is widely accepted that the domination of financial markets by institutional investors is another reason for the exorbitant increase in trading frequency. Chordia et al. (2009) document that turnover has increased the most for stocks with high levels of institutional ownership, confirming that institutional investors have played an important role in that respect. This trading behaviour can be partly explained by the volatile behaviour of equity fund flows (Chordia et al. 2009), which may have been caused, to an extent, by the abolition of front and back-end loads that were previously charged by a significant portion of equity funds. ${ }^{11}$

This trend has been strengthened by the emergence of particular types of institutional investors, such as hedge funds, that employ quantitative strategies (e.g. algorithmic trading),

\footnotetext{
${ }^{10}$ For example, Nielsson (2009) discusses the liquidity effects due to the creation of Euronext. Moreover, Brockman, Chung and Perignon (2009) provide robust evidence for the existence of commonality in liquidity across exchanges on a global basis.

${ }^{11}$ See the Investment Company Institute Factbook 2009 for an analysis of load fees incurred by equity fund holders. The Factbook is available at http://www.icifactbook.org/
} 
heavily relying on intraday trading (Khandani and Lo (2007)). ${ }^{12}$ The very short stock holding horizon of certain groups of institutional investors has been repeatedly used as a means of criticism for their passivity and lassitude regarding corporate governance issues (Bogle (2005)). Moreover, the dramatic growth of assets under management by institutional investors during the last decades as well as their increased trading activity had been reflected by the increase in the proportion of equities traded in blocks (Madhavan and Chang (1997), Stapledon (1996)). Nevertheless, as Chordia et al. (2009) and O' Hara and Ye (2009) note, the introduction of electronic markets has allowed institutional investors to break up large orders and execute them in smaller increments but at a higher frequency in the very recent years.

\section{Data and Descriptive Statistics}

The initial sample we consider consists of all common stocks listed on the London Stock Exchange for the period from January 1991 to December 2008. Our analysis covers both presently listed and dead stocks (i.e. stocks of firms that were de-listed at some point during the sample period), and hence our dataset is free of any potential survivorship bias. We impose several screening criteria to our initial sample to minimize the impact of outliers. In particular, we exclude firms with market value less than $£ 10$ million. Furthermore, we exclude stocks for which we cannot obtain price data for at least 36 consecutive months that are necessary to calculate beta values. Finally, following conventional practice in UK stock market studies (see e.g. Fletcher and Kihanda (2005)), we further exclude unit trusts, investment trusts and ADRs. Our final dataset comprises of an average of 933 stocks in each month.

For each share we use Thomson DataStream to obtain daily information on a wide set of variables including trading volume (number of shares traded for a stock on a particular day),

\footnotetext{
${ }^{12}$ The financial press commonly refers to the excessive trading of hedge funds. See, for example, the artidle entitled "In Their Prime”, Economist, June 1, 2006.
} 
turnover (ratio of trading volume to the number of shares outstanding), market value (share price multiplied by the number of outstanding ordinary shares) and price-to-book value ratio (share price divided by the book value per share). We also collect daily data on the opening, closing, bid, ask and mid share prices. In our study we mainly utilize two alternative price impact ratios: the RtoV ratio proposed by Amihud (2002), which is calculated as the monthly average ratio of the absolute daily return to the corresponding British pound trading volume, and the RtoTR ratio, which is calculated as the monthly average ratio of the absolute daily return to the corresponding turnover rate. ${ }^{13}$

For the estimation of the asset pricing models we need to construct the size, value and momentum factors. For the size factor, we sort all listed stocks according to their market capitalization at month $t-1$ and we assign the top $30 \%$ (value-weighted) to the "Big size" portfolio and the bottom $30 \%$ to the "Small size" portfolio. The difference between the returns of these two portfolios at month $t$ yields the size factor $\left(S M B_{t}\right)$ return. For the momentum factor we rank all available stocks at month $t$ - 1 according to their returns from month $t-13$ to $t-2$. The top $30 \%$ (value-weighted) of these stocks were classified as "Winners" and the bottom $30 \%$ as "Losers". The spread of their monthly returns at month $t$ is taken as the momentum factor return $\left(M O M_{t}\right)$. Following Cuthbertson, Nitzsche and O' Sullivan (2008), we calculate the value factor $\left(H M L_{t}\right)$ as the spread between the monthly returns of the MSCI UK Growth and the MSCI UK Value indices. Finally, we use FTSE All Share as the market index and the 1-month UK interbank rate as the risk-free rate.

To provide some initial insights on the usefulness of the RtoTR ratio and its superior ability to disentangle the size and liquidity effects in comparison to the RtoV ratio, we compute and analyze the Spearman rank correlations for the variables RtoTR, RtoV and Market Value $(M V)$ for a typical month of our sample (January 2000). ${ }^{14}$ According to our findings, the Spearman correlation coefficient between the RtoTR price impact ratio and $M V$

\footnotetext{
${ }^{13}$ See sections 2.1 and 2.2 for details.

${ }^{14}$ The results remain qualitatively similar when other months are considered.
} 
is only 0.006 , which is not significantly different from zero. On the contrary, RtoV is highly correlated to $M V$ with a correlation coefficient of -0.846 , which is significantly different from zero. These early findings clearly indicate that the price impact ratio proposed in this study does not exhibit the inherent size bias of the RtoV ratio.

To check how RtoTR relates to traditional measures of trading frequency and trading costs, we also calculate the Spearman rank correlation coefficient between RtoTR, RtoV, BidAsk spread $(B A)$ and Turnover Rate $(T R)$. The results lead to several interesting conclusions. First, RtoTR is positively correlated with $B A$, with a coefficient of 0.324 and negatively correlated with $T R$ with a coefficient of -0.581 . This finding supports our previous argument that RtoTR is likely to capture two different dimensions of illiquidity, namely trading cost (proxied by $B A$ ) and trading frequency (proxied by $T R$ ). Interestingly, the results indicate that this is not the case for RtoV, which is negatively correlated with $T R$ at -0.326 but also negatively correlated with $B A$ at -0.114 . Another interesting finding refers to the negative but relatively low rank correlation coefficient between $B A$ and $T R$ (at -0.152). This is consistent with the view that these two variables are likely to capture two different dimensions of liquidity. Therefore, it is argued that RtoTR may help capture some important information that conventional spread measures are unable to adequately incorporate in isolation, since this price impact ratio is able to combine the unique information contained in $B A$ and $T R$ (see also Liu (2006)).

The next step involves classifiying stocks into decile portfolios according to each of the two price impact ratios (RtoV and RtoTR) and analyzing these portfolios' characteristics (e.g. performance, average market value, beta and price-to-book value ratio). Specifically, at the end of month $t-1$, stocks are alternatively sorted according to their average RtoV and RtoTR values in that month into ten portfolios. Portfolio 1 (P1) includes stocks with the smallest values of RtoV (or RtoTR) while Portfolio 10 (P10) contains stocks with the highest values of RtoV (or RtoTR), and their excess return in month $t$ (i.e. post-ranking returns) is calculated. 
For robustness, we calculate both equally weighted and value weighted portfolio returns in excess of the risk free rate. Portfolios are rebalanced on a monthly basis.

Table 1 presents the descriptive statistics of the ten portfolios constructed on the basis of RtoV. The results presented in Panel A, referring to the period from February 1991 to December 2008, point to the existence of a non-negligible returns' differential, since the spread between P10 and P1 is significantly positive. Moving from P1 to P10, the average portfolio return considerably increases, though not strictly monotonically. This pattern holds both for equally weighted and for value weighted portfolios' returns. The level of this differential is $13.390 \%$ p.a. $(t=3.093)$ for equally weighted returns and $6.215 \%$ p.a. $(t=1.517)$ for value weighted returns. We then conduct a sub-period analysis. Panel B presents the portfolios' descriptive statistics for the period from February 1991 to December 1999, while Panel C contains the corresponding results for the period from January 2000 to December 2008. These results suggest that the P10-P1 equally weighted spread is $13.405 \%$ p.a. $(t=2.151)$ in the first sub-period and $13.375 \%$ p.a. $(t=2.213)$ in the second sub-period. However, the value weighted spread is economically and statistically significant only for the first sub-period, equal to $9.736 \%$ p.a. $(t=1.717)$, while during the second sub-period is found to be equal to $2.726 \%$ p.a., but statistically insignificant $(t=0.461) .{ }^{15}$

Another interesting observation from Table 1 is that in all periods under examination, the average market capitalization of stocks in each portfolio decreases almost monotonically as we move from portfolio P1 to portfolio P10. This pattern confirms the previous argument that RtoV is by construction highly negatively correlated with market capitalization. The apparent strong relationship between RtoV and $M V$ raises legitimate concerns about whether the spread observed in Table 1 can be identified as a size or an illiquidity premium. The rest of the findings in Table 1 suggest that portfolios composed of stocks with low RtoV values tend to have higher average price-to-book value ratios than those composed of stocks with

\footnotetext{
${ }^{15}$ Ben-Rephael et al. (2008) report a similar decreasing trend for the premium yielded by NYSE stocks with high RtoV values relative to stocks with low RtoV values.
} 
high RtoV values. Finally, the average beta of the stocks, calculated using a 36-month rolling window, is close to one and does not considerably vary across the ten portfolios.

Table 2 presents the corresponding characteristics of the ten portfolios constructed on the basis of the RtoTR measure. The analysis based on the new price impact ratio produces results that are substantially different from the ones obtained after using the RtoV ratio. In particular, portfolio P1 yields a much higher average return (both for equal and valueweighted portfolios) as compared to portfolio P10. The P1-P10 equally weighted spread is $15.395 \%$ p.a. $(t=5.156)$ over the whole sample period, $17.575 \%$ p.a. $(t=4.361)$ over the period February 1991-December 1999 and $13.235 \%$ p.a. ( $t=2.999)$ over the period January 2000December 2008. When value weighted returns are considered, the corresponding premium for these periods is as high as $12.469 \%$ p.a. $(t=3.896), 11.050 \%$ p.a. $(t=2.957)$ and $13.875 \%$ p.a. $(t=2.668)$ respectively. These findings are consistent with the view that the trading frequency effect dominates the transaction costs effect and, therefore, stocks with low RtoTR values yield ceteris paribus higher average returns relative to stocks that exhibit high RtoTR values.

Another finding that deserves emphasis relates to the average market capitalization of the stocks in each of these portfolios. This does not exhibit any monotonic pattern across the ten portfolios, confirming that the RtoTR spread does not reflect a size premium. The validity of this argument is further reinforced by the fact that not only the spread P1-P10 is high but the same holds for the spreads P1-P9, P1-P8 and P1-P7, which involve relatively larger stocks on their long side and yield premiums higher than $10 \%$ p.a. (in terms of both equally weighted and value weighted returns). These results hold in all time periods considered (see Panels B and C in Table 2). Finally, the results in Table 2 show that stocks in P1 display the highest average price-to-book value ratio, while stocks in P10 exhibit the lowest ones (except for the period January 2000-December 2008). Finally, the differences in average stocks' betas across the ten portfolios are minimal.

Taken as a whole, the descriptive statistics suggest that Amihud's (2002) price impact ratio, despite of it usefulness to capture the transaction costs effect, it has two major 
weaknesses: first, it suffers from a severe size bias and, secondly, it fails to capture the trading frequency effect. On the contrary, the RtoTR ratio proposed in this study is free of the size bias and controls for both the trading frequency and the trading cost effects. To properly establish the existence of the premium yielded by stocks with low RtoTR values relative to stocks with high RtoTR values, we examine in the following section the risk-adjusted performance of these portfolios by conducting appropriate asset pricing tests.

\section{Asset Pricing Tests}

\subsection{Risk-adjusted performance}

We estimate the abnormal performance of the portfolios constructed on the basis of the RtoV and RtoTR ratios correspondingly using three asset pricing models. Firstly, we estimate Jensen's alpha from the CAPM:

$$
r_{i t}-r_{f t}=\alpha_{i}+\beta_{i, M K T} M K T_{t}+\varepsilon_{i t}
$$

where $r_{i t}$ is the return of portfolio $i$ in month $t, r_{f t}$ is the risk-free rate for month $t$ and $M K T_{t}$ is the excess market portfolio return, $\left(r_{m t}-r_{f t}\right)$, in month $t$. Secondly, we compute FamaFrench alpha, i.e. the intercept of the 3-factor Fama-French (1993) model:

$$
r_{i t}-r_{f t}=\alpha_{i}+\beta_{i, M K T} M K T_{t}+\beta_{i, S M B} S M B_{t}+\beta_{i, H M L} H M L_{t}+\varepsilon_{i t}
$$

where $S M B_{t}$ and $H M L_{t}$ stand for the size and value risk factors respectively. Thirdly, we estimate Carhart's alpha, i.e. the intercept of the 4-factor Carhart (1997) model:

$$
r_{i t}-r_{f t}=\alpha_{i}+\beta_{i, M K T} M K T_{t}+\beta_{i, S M B} S M B_{t}+\beta_{i, H M L} H M L_{t}+\beta_{i, M O M} M O M_{t}+\varepsilon_{i t}
$$

where $M O M_{t}$ stands for the momentum risk factor. ${ }^{16}$ In order to test for the joint significance of the ten portfolios' alphas and to mitigate potential errors-in-variable problems we use a system-based estimation. In particular, we report alphas estimated via GMM with standard errors corrected for heteroscedasticity and serial correlation.

\footnotetext{
${ }^{16}$ Section 3 provides detailed information on how the factors MKT, SMB, HML and MOM have been constructed.
} 
For comparability purposes, we report the results for both the RtoV and the RtoTRsorted portfolios. Table 3 reports the alphas of the ten value-weighted portfolios formed on the basis of the RtoV ratio. As shown in Panel A, which refers to the period February 1991December 2008, the CAPM cannot completely account for the premium that relates to RtoV premium. Specifically, P1 yields the lowest Jensen alpha (0.90\% p.a.), while P10 yields the highest one $(7.49 \%$ p.a.), leading to a premium of $6.58 \%$ p.a. $(t=1.64)$. However, this weak evidence for the existence of this premium disappears when Fama-French or Carhart alphas are considered as measures of risk-adjusted performance. In particular, the Fama-French alpha of the P10-P1 spread is $3.83 \%$ p.a., while the corresponding Carhart alpha of this spread is $3.84 \%$ p.a. The corresponding $t$ values of 1.13 and 1.02 denote that, in both cases, these premia are not statistically significant. To identify which of the three added risk factors causes the disappearance of the premium, we successively add them and re-estimate the models. Unreported results indicate that the initially documented premium disappears in any specification that includes the size factor.

In panels $\mathrm{B}$ and $\mathrm{C}$ of Table 3 we present the corresponding results from the sub-period analysis, covering the periods February 1991-December 1999 and January 2000-December 2008, respectively. The evidence supports the existence of a weak premium under the CAPM specification in the first sub-period (i.e. the P10-P1 spread has an abnormal return of $8.88 \%$ p.a., though it is not statistically significant). The premium is almost halved in the second subperiod (i.e. the P10-P1 spread yields an abnormal return of $4.94 \%$ p.a. and remains statistically insignificant). The results obtained from the Fama-French and Carhart models also lead to several interesting conclusions. Specifically, the Fama-French alpha of the P10P1 spread is found to be large and positive at $10.19 \%$ p.a. $(t=2.33)$ over the February 1991December 1999 period but negative and insignificant at $-2.27 \%$ p.a. $(t=-0.54)$ over the period January 2000 to December 2008. Similar are the results when the Carhart model is employed.

Table 4 presents the value weighted alphas of the ten portfolios constructed on the basis of the RtoTR price impact ratio. Panel A refers to the period from February 1991 to December 
2008; P1 is the portfolio that yields the highest estimated alpha for all three asset pricing models considered. Moving from P1 to P10, alpha estimates are substantially reduced, though not monotonically in all cases. P10 yields the lowest Carhart alpha (-6.85\% p.a.) and the third lowest Jensen and Fama-French alpha (-3.89\% p.a. and $-5.78 \%$ p.a., respectively). The premium generated by the P1-P10 portfolio is significantly positive and ranges from $12.20 \%$ p.a. $(t=3.65)$ under the CAPM specification to $13.58 \%$ p.a. $(t=4.22)$ under the Fama-French model. These results confirm, in risk-adjusted terms, the superior performance of stocks with low RtoTR values relative to stocks with high RtoTR that we initially reported for unadjusted returns in Table 2. To test the joint significance of the estimated alphas for all of the ten portfolios constructed, we use a Wald test that is equivalent to the Gibbons, Ross and Shanken (1989) test. For every model specification considered the Wald test overwhelmingly rejects the null hypothesis of jointly zero alpha estimates. This result shows that portfolios constructed on the basis of the RtoTR ratio yield abnormal returns that cannot be accounted for by the commonly used asset pricing models.

As we have previously mentioned, the explanation for the reversal of the portfolios' returns ordering relative to Amihud's ratio is due to the incorporation of trading frequency in the proposed price impact ratio. Our findings clearly indicate that even after adjusting for market, size, value and momentum risk, stocks with very high turnover rates and low RtoTR values dictate large premia. This suggests that the trading frequency effect overwhelmingly dominates the transaction costs effect and, also, that even low transaction costs may yield high expected returns if they are frequently incurred. This is in line with the fundamental theoretical result of Amihud and Mendelson (1986a) and, also, consistent with the evidence that transaction costs have been considerably reduced, while trading frequency has dramatically increased during the last two decades. Overall, our findings suggest that neglecting the trading frequency effect will be misleading, while examining each effect in isolation may lead to inconclusive results; one should take into account these two effects jointly in conducting asset pricing tests. 
The previous findings are confirmed when a sub-period analysis is conducted. In particular, the results in Panels B and C point to the existence of a statistically significant P1P10 risk-adjusted premium in both sub-periods examined and for every asset pricing model employed. In other words, the outperformance of the strategy that sells short stocks with high RtoTR values and invests in stocks with low RtoTR values cannot be attributed to any of the size, value and momentum risk factors. This result, taken together with the fact that not only the P1-P10 spread but also the P1-P9 and P1-P8 spreads are greater than 9\% p.a. and statistically significant under all model specifications and for every period considered, provides further support for the importance of the trading frequency effect and strengthens the case for using the proposed price impact ratio. Moreover, similar to the results presented in Panel A, the Wald tests strongly reject again the null hypothesis of jointly zero alpha estimates for the ten portfolios in every sub-period and model specification considered.

For robustness, we report in Table 5 the risk-adjusted performance of equally-weighted portfolios constructed on the basis of the RtoTR ratio. Panel A refers to the whole sample period, while Panels B and C refer to the two sub-periods considered. All of the previously reported results are robust to calculating portfolios' returns using equal weights.

\subsection{Cross-sectional evidence}

Given the time-series evidence for the abnormal performance of portfolios constructed on the basis of the RtoTR price impact ratio (presented in the previous section), we are motivated to examine whether a Price Impact (PI) factor, once added to the traditional asset pricing model, helps explain the cross-sectional variation in these portfolios' returns. We define the PI factor as the spread return of value weighted portfolios P1-P10, constructed on the basis of the RtoTR ratio. As a first step, we perform the traditional two-stage Fama-MacBeth (1973) regressions using information from all of the ten RtoTR-sorted portfolios. This exercise will shed light on whether the risk premium associated with this factor is positive and statistically significant. 
The first stage of the Fama-MacBeth approach involves the estimation of betas from time-series regressions of excess portfolio returns on a set of risk factors. The most general among the model specifications we consider is the augmented Carhart model, given by:

$$
r_{p t}-r_{f t}=\alpha_{p}+\beta_{p, M K T} M K T_{t}+\beta_{p, S M B} S M B_{t}+\beta_{p, H M L} H M L_{t}+\beta_{p, M O M} M O M_{t}+\beta_{p, P I} P I_{t}+e_{p t}
$$

where $r_{p t}$ is the return of portfolio $p$ at time $t, r_{f t}$ is the monthly risk-free rate for month $t$, and MKT, SMB, HML, MOM and PI refer to the market, size, value, momentum and price impact factors, as previously defined. As it is common practice in the literature, in the first stage we estimate a time-series of factor loadings for each of the ten portfolios using rolling windows of 60 monthly observations. However, for the early sample periods we start computing these betas when there are at least 36 observations.

The second stage involves the estimation of monthly cross-sectional regressions of the ten excess portfolios' returns on the corresponding betas that were estimated in the first-stage. The cross-sectional regression model is:

$$
r_{p t}-r_{f t}=\lambda_{0}+\lambda_{M K T} \hat{\beta}_{p, M K T}+\lambda_{S M B} \hat{\beta}_{p, S M B}+\lambda_{H M L} \hat{\beta}_{p, H M L}+\lambda_{M O M} \hat{\beta}_{p, M O M}+\lambda_{P I} \hat{\beta}_{p, P I}+w_{p t}
$$

where now lambdas represent the risk premium coefficients associated with each beta. The main hypothesis we test is whether the time-series average of the estimated coefficients $\lambda_{5}$ is positive and statistically significant, which is perceived as evidence that the PI factor is priced. For robustness purposes, apart from standard Fama-MacBeth $t$-statistics for the lambda coefficients, we follow Shanken (1992) to calculate $t$-statistics using standard errors that have been corrected for the error-in-variables bias, arising due to the fact that the factor loadings used as regressors in (8) are pre-estimated rather than being the true, unobservable ones.

Table 6 presents the estimated lambda coefficients for the ten value-weighted portfolios sorted according to the RtoTR ratio. For comparability purposes, we report results for the three asset pricing models that are most commonly used (CAPM, Fama-French and Carhart models), once they have been augmented by the PI factor. Panel A reports the results for the 
unrestricted model where $\lambda_{0}$ can take any value. The results support the existence of a large positive and statistically significant premium $\left(\lambda_{P I}\right)$. Specifically, we find that when we add the PI factor to the CAPM, its estimated coefficient $\left(\lambda_{P I}\right)$ is positive at 0.81 and statistically significant at the $5 \%$ level. The coefficient $\lambda_{P I}$ remains positive and statistically significant at the $1 \%$ level when the PI factor is added to the Fama-French and Carhart models, taking values of 0.97 and 0.94 , respectively. The statistical significance of these coefficients remains intact even when we use Shanken-corrected standard errors, which are typically larger. Moreover, the fact that none of the models' intercept $\left(\lambda_{0}\right)$ is found to be statistically significant points to the conclusion that the PI-augmented models are not mis-specified.

The pre-last column in Panel A of Table 6 reports the adjusted R-squared coefficients, while the last column informs us on the increase in the adjusted R-squared coefficients due to the addition of PI factor to the model. ${ }^{17}$ Given the commonly reported values in the literature, our results show that the augmented models have a quite good explanatory power over the cross-section of these RtoTR portfolios' returns. Standard models that do not include the PI factor would not only be misspecified since $\lambda_{P I}$ is statistically significant in every case, but they would also have a much lower explanatory power. In Panel B of Table 6, we report the estimated lambda coefficients from the second stage cross-sectional regression under various specifications, once we have restricted $\lambda_{0}$ to be equal to its zero theoretical value. The results are qualitatively similar to the ones reported in Panel A, supporting the existence of a strong and statistically significant premium that reaches the level of $9.70 \%$ p.a. for the PI-adjusted CAPM, $11.20 \%$ p.a. for the PI-adjusted Fama-French model and $11.10 \%$ p.a. for PI-adjusted Carhart model (the corresponding $\lambda_{P I}$ coefficients are $0.81,0.93$ and 0.92 respectively).

As an alternative to the Fama-McBeth procedure, we also estimate the premium associated with the PI factor via the GMM procedure described in Cochrane (2005b). In particular, defining $\mathbf{r}_{\mathbf{t}}^{\mathbf{x}}$ to be the $10 \mathrm{x} 1$ vector containing the excess returns of the ten test

\footnotetext{
${ }^{17}$ Results for all the other model specifications considered are available upon request.
} 
portfolios, $\boldsymbol{\beta}_{0}$ the $10 x 1$ vector of constants, $\mathbf{B}=\left[\begin{array}{ll}\beta_{M K T} & \beta_{P I}\end{array}\right]$ the $10 \times 2$ matrix of portfolios' returns sensitivities to the market and PI factors and $\mathbf{F}_{\mathbf{t}}=\left[\begin{array}{lll}M K T_{t} & P I_{t}\end{array}\right]$ the $2 \times 1$ vector containing the realizations of these factors, then the PI-adjusted CAPM can be written as:

$$
\mathbf{r}_{\mathbf{t}}^{\mathbf{x}}=\boldsymbol{\beta}_{0}+\mathbf{B F} \mathbf{F}_{t}+\mathbf{e}_{\mathbf{t}}
$$

If the test portfolios are priced by their returns' sensitivities to the traded factors, then their expected returns should satisfy:

$$
\mathbf{E}\left(\mathbf{r}^{\mathbf{x}}\right)=\mathbf{B} \boldsymbol{\lambda}
$$

where $\lambda=\left[\begin{array}{ll}\lambda_{M K T} & \lambda_{P I}\end{array}\right]$ is now a $2 \times 1$ vector containing the premia on the corresponding factors. Let $\boldsymbol{\theta}$ denote the set of unknown parameters $\left[\begin{array}{lll}\boldsymbol{\beta}_{0} & \mathbf{B} & \lambda\end{array}\right]$. The GMM estimator of $\theta$ minimizes the quadratic form $g(\boldsymbol{\theta})^{T} \mathbf{W} g(\boldsymbol{\theta})$, where $g(\boldsymbol{\theta})=(1 / T) \sum_{t=1}^{T} f_{t}(\boldsymbol{\theta})$,

$$
f_{t}(\boldsymbol{\theta})=\left[\begin{array}{l}
\left(\mathbf{r}_{\mathbf{t}}^{\mathrm{x}}-\boldsymbol{\beta}_{0}-\mathbf{B} \boldsymbol{\lambda}\right) \\
\left(\mathbf{r}_{\mathbf{t}}^{\mathrm{x}}-\boldsymbol{\beta}_{0}-\mathbf{B} \boldsymbol{\lambda}\right) \otimes \mathbf{F}_{t} \\
\left(\mathbf{r}_{\mathbf{t}}^{\mathrm{x}}-\mathbf{B} \boldsymbol{\lambda}\right)
\end{array}\right]
$$

and $\mathbf{W}$ is a consistent estimator of the optimal weighting matrix. ${ }^{18}$

Using the ten RtoTR-sorted portfolios as test portfolios, we get a statistically insignificant market risk premium estimate, $\lambda_{M K T}=0.15$ ( $t$-stat=0.47) on a monthly basis. On the other hand, the premium corresponding to the PI factor is positive and statistically significant, $\lambda_{P I}=1.58$ (t-stat=3.74). This finding highlights the importance of augmenting the CAPM with the PI factor as well as confirms the previous evidence for the high premium it commands. Finally, given these GMM estimates, we plot the actual mean excess returns versus the model predictions in order to show the goodness of fit of the PI-adjusted CAPM. As one can observe from Figure 1, the augmented model does extremely well in pricing the ten RtoTR-sorted portfolios, since they lie along the $45^{0}$ line.

\footnotetext{
${ }^{18}$ In particular, we have employed the Newey-West procedure for its estimation.
} 


\section{Further results}

\subsection{Momentum and Size premia}

A recurrent issue in the asset pricing literature refers to the identification of the underlying risk factors that may explain the well-established size and momentum anomalies. ${ }^{19}$ Given that RtoTR-sorted portfolios yield abnormal risk-adjusted returns, we are motivated to examine whether the size and momentum anomalies remain intact once the PI factor is added to the commonly used asset pricing models. To this end, we alternatively sort UK listed stocks in month $t-1$ on the basis of their market capitalization and past performance (returns from month $t-13$ to month $t-2$ ), construct the corresponding decile portfolios and calculate their value-weighted returns in month $t$. Using these portfolios' returns, we estimate their abnormal performance by adding the PI factor to each of the three asset pricing models we considered in Section 4.1 (see models (4) to (6)). We opt for a system-based approach and estimate these models via GMM with standard errors corrected for heteroscedasticity and serial correlation.

Panel A of Table 7 presents the risk-adjusted performance of the spread strategy that goes long past winners and short past losers (P10-P1) for each of the six asset pricing models considered. Apart from the whole sample period, we have also considered two sub-periods. When we employ the standard CAPM, Fama-French and Carhart models, the P10-P1 momentum strategy delivers a positive and statistically significant abnormal return of $22.78 \%$ p.a. $(t=2.78), 25.12 \%$ p.a. $(t=3.73)$ and $9.44 \%$ p.a. $(t=1.97)$ respectively. This evidence confirms the well known momentum anomaly in our sample too. Interestingly, adding the PI factor to each of the model specifications substantially reduces the magnitude of the abnormal returns that this strategy yields. Most importantly, when we employ the augmented Carhart model, the alpha of the P10-P1 strategy is more than halved to $4.67 \%$ p.a. and becomes

\footnotetext{
${ }^{19}$ For example, it has been recently argued that liquidity risk may well provide a solution to these puzzles. Amihud (2002) and Acharya and Pedersen (2005) argue that the size anomaly evaporates once a liquidityadjusted asset pricing model is employed. In the same spirit, Pastor and Stambaugh (2003) document that the momentum premium is more than halved when a liquidity factor is added to the Fama-French model.
} 
statistically insignificant. The alphas derived from the PI-augmented CAPM and FamaFrench model remain statistically significant but are considerably smaller in comparison to the ones derived from the standard specifications (16.71\% p.a. vs. $22.78 \%$ p.a. and $19.81 \%$ p.a. vs. $25.12 \%$ p.a. respectively). Similar are the findings for the sub-period from February 1991 to December 1999. For the second sub-period, January 2000 to December 2008, the momentum anomaly becomes particularly weak. The addition of the PI factor to any considered model reduces further the momentum strategy's alphas and renders them statistically insignificant. In the spirit of Pastor and Stambaugh (2003), these findings support the view that certain aspects of liquidity risk (e.g. trading costs and trading frequency) may explain to a great extent momentum strategies' profits.

Panel B of Table 7 contains the corresponding results for the risk-adjusted performance of the spread strategy that goes long small cap stocks and sells short big cap stocks (P1-P10). For the whole sample period, the CAPM fails to account for the size effect, since the Jensen alpha of this strategy is as high as $17.56 \%$ p.a. $(t=2.69)$. As expected, the size premium is substantially reduced under the Fama-French and Carhart specifications but remains statistically significant at $14.66 \%$ p.a. $(t=2.76)$ and $11.85 \%$ p.a. $(t=2.55)$ respectively. When the PI factor is added to these models, the abnormal performance of the P1-P10 strategy actually increases and varies from $18.86 \%$ p.a. $(t=3.93)$ for the PI-augmented Carhart model to $27.02 \%$ p.a. $(t=4.37)$ when the PI-augmented CAPM is employed. The results are similar for the sub-periods February 1991 to December 1999 and January 2000 to December 2008. These findings lead to the conclusion that a price impact risk factor constructed on the basis of the RtoTR ratio cannot explain the abnormal returns that the size strategy delivers. This may be explained by the fact that the RtoTR ratio is free of a size bias.

\subsection{An investment perspective}

It was documented in Section 4.1 that portfolios constructed on the basis of the RtoTR price impact ratio exhibit a superior performance, even when their potential exposure to market, 
size, value and momentum risk is taken into account. This result essentially implies that expected returns should reflect an extra dimension of risk and, as a result, if added to an asset universe that already contains the MKT, SMB, HML, MOM factors, the traded PI factor may further increase the maximum Sharpe ratio that a mean-variance investor can achieve. The relationship between multi-beta asset pricing and mean-variance efficiency of some combination of benchmark portfolios is well-established (see Merton (1973) for an early treatment and Cochrane (2005b, Ch. 5) for a rigorous textbook analysis)). Given this observation, in this section we consider a simple mean-variance asset allocation setup to examine how the addition of this PI factor enhances the mean-variance investor's opportunity set. $^{20}$

More specifically, we calculate the weights of the five traded factors (MKT, SMB, HML, MOM and PI) in the ex post tangency portfolio as well as its corresponding ex post Sharpe ratio. Various combinations of these factors are considered in order to identify the marginal contribution of the PI factor. Panel A of Table 8 contains the results for the period February 1991- December 2008. For the trivial case where only the MKT factor is available, the investor assigns $100 \%$ of her portfolio to this asset, achieving an ex post Sharpe ratio of $\mathrm{S}^{*}=-0.036$ on a monthly basis. A negative Sharpe ratio may not be appealing, but it is a direct consequence of the fact that the average excess monthly returns of the FTSE All Share, the market index, have been negative for the period under examination. Adding the SMB factor, that bears a positive average monthly premium, leads to a Sharpe ratio of $S^{*}=0.083$. The addition of the HML factor induces a negligible only increase in the achievable ex post

\footnotetext{
${ }^{20}$ As mentioned in Pastor and Stambaugh (2003), utilizing the mean-variance efficiency setup by no means imply that the tangency portfolio is the optimal allocation for an investor operating in a world that gives rise to multi-beta pricing. It is well known since Merton (1973) that in a world with multiple risk factors optimal portfolios may contain additional hedging demands. Nevertheless, the mean-variance framework, being the most studied setup in portfolio choice, is still of interest to many investors; if the addition of this extra traded factor leads to considerable enhancement in mean-variance terms, then one may expect that it will be highly beneficial for more sophisticated asset allocation schemes too.
} 
Sharpe ratio. In this three-factor setup, the SMB factor is the dominant asset in the tangency portfolio, to the extent that the investor holds a leveraged position by selling short the MKT factor. More interestingly, the addition of the MOM factor considerably enhances the opportunity set of the investor. This factor becomes now the dominant asset in the tangency portfolio, since the investor assigns to it $59.18 \%$ of her wealth, while the ex post Sharpe ratio increases to $S^{*}=0.24$.

Proceeding to asset menus that include the PI factor, striking results are obtained. Allowing the investor to combine the PI factor with the MKT factor, the Sharpe ratio becomes $S^{*}=0.266$, higher than what an investor can achieve in a four-factor universe à la Carhart (1997). The investor assigns almost all of her wealth in the new factor; this is an anticipated outcome given the disappointing negative excess market returns during the examined period. A harder challenge is to modify portfolio choices and increase Sharpe ratios by introducing PI in the presence of the Fama-French or Carhart factors. Facing this challenge, the PI factor plays an important role in the tangency portfolios constructed in these two cases. In particular, the investor allocates to PI $33.11 \%$ of her wealth in the presence of MKT, SMB, HML and $17.54 \%$ if MOM is also available. Even more intriguing are the corresponding increases in the Sharpe ratios. In the first case, the inclusion of PI quadruples $\mathrm{S}^{*}$ to 0.333 , while in the second case $\mathrm{S}^{*}$ is increased by more than half, reaching $\mathrm{S}^{*}=0.398$. There are two main reasons for this striking enhancement in the opportunity set. The first is the attractive mean-variance profile of the PI factor, as presented in Table 2. The second is its correlation structure with the other available factors. Panel A of Table 9 presents the pairwise correlation coefficients of the five available factors, illustrating that the returns of the employed PI factor have a negligible correlation with HML and MOM returns, while they are negatively correlated with MKT and SMB returns. In other words, the premium associated with the PI does not just mimick other factors' premia; it represents genuine outperformance, while the PI factor can also serve as a helpful diversification tool for the mean-variance optimizer. These results show that besides the statistical significance of the premium 
documented within an asset pricing framework, there is scope and value in exploiting this premium in a portfolio choice setup, above and beyond the size, value and momentum premia.

Even though it is a direct consequence of the ongoing financial crisis, the existence of negative average monthly excess returns for the market portfolio may cast doubt on the robustness of our previous results. To address this concern, we repeat this asset allocation exercise excluding the last two years of our sample period. Results are reported in Panel B of Table 8. For the sub-period February 1991- December 2006, average returns for MKT are positive, leading to the familiar outcome of a positive ex post Sharpe ratio $\left(\mathrm{S}^{*}=0.023\right)$ for the trivial case where MKT is the only available risky asset. For the combinations of MKT, SMB, HML and MOM factors, results are analogous to the ones obtained for the whole sample period. The only difference is that the incentive to sell short MKT is now almost neutralized due to the positivity of its premium, while the Sharpe ratios are also slightly higher. Most importantly, our previous conclusions for the role of the PI factor are robust to the exclusion of the last two years of our sample. The mean-variance investor seeks to allocate considerable portions of her wealth to this traded asset even in the presence of MOM $(26.67 \%$ in the presence of MKT, HML, SMB and $17.45 \%$ in case MOM is also available) and the ex post Sharpe ratios become even higher for all of the cases considered.

The previous argument for the diversification role of the PI factor carries through for this sub-period too, given the pairwise correlation coefficients of these factors presented in Panel B of Table 9. As a further robustness check, we alternatively construct the PI factor using equal weighted returns of the portfolios formed on the basis of the RtoTR price impact ratio and then repeat the asset allocation exercise. The results, available upon request, point to an even more important role for the equally-weighted PI factor and to a further increase in the ex post Sharpe ratios. These results stem from the even higher premium that the spread of the equally-weighted portfolios P1-P10 yields in comparison to its value-weighted counterpart and its similar correlation structure with respect to the other traded factors. 


\section{Summary}

In this study we propose a new price impact ratio, RtoTR, as an alternative to the most commonly used one in the market microstructure literature, Amihud's (2002) return-tovolume ratio $($ RtoV). This new ratio, RtoTR, essentially modifies $R t o V$ by substituting trading volume in its denominator with the turnover ratio for each security. The rationale behind the development of this measure is twofold. First, the trading volume of each stock in monetary terms is by construction positively related to its market value, implying that it is not comparable across stocks with different market values. This fact leads to a severe size bias that is present in Amihud's measure, limiting its ability to separate illiquidity from size effects in asset pricing. Our measure does not suffer from this size bias because there is no a priori reason why the turnover ratio of a stock should be correlated with its market capitalization. Second, RtoTR is not just a quick methodological fix to overcome the shortcomings of RtoV. Instead, there is a solid theoretical foundation in attempting to encapsulate stocks' crosssectional variability in trading frequency. As Amihud and Mendelson (1986a) point out, an asset's expected return is determined by both the cost and the frequency of transactions. Recent developments in financial markets have led to a substantially higher trading activity and correspondingly lower trading costs, rendering necessary the use of a price impact ratio that explicitly takes into account the cross-sectional variation in stocks' turnover ratios.

Using daily data for all listed companies on the London Stock Exchange over the period January 1991- December 2008, we empirically examine the importance of the suggested price impact ratio for asset pricing. In particular, we report that stocks with low RtoTR values yield significantly higher post-ranking returns as compared to stocks with high RtoTR values. This finding holds even when we control for market, size, value and momentum risk factors, indicating genuinely abnormal performance. Our results support the argument that it is the compound effect of trading frequency and transaction costs that matters for asset pricing, not each feature in isolation. 
Strengthening further the case for the adoption of the modified price impact ratio, RtoTR, we empirically confirm that it this free of a size bias. On the other hand, Amihud's (2002) ratio is found to be highly negatively correlated with market capitalization. This forces the conclusion that small stocks are necessarily illiquid. We provide ample evidence that the initial differential return between a portfolio of stocks with high RtoV and a portfolio of stocks with low RtoV is subsumed once an asset pricing model that includes a size factor is employed.

Finally, a Price Impact (PI) factor, defined as the spread between the return of the decile portfolio of stocks with the lowest RtoTR values and the return of the decile portfolio of stocks with the highest RtoTR, allows us to partly explain the momentum but not the size anomaly. Moreover, this traded factor is found to be of great value for a mean-variance investor, since it can considerably increase the feasible ex post Sharpe ratio of the tangency portfolio. These results are robust to a wide variety of sensitivity tests. 


\section{References}

Acharya, V., Pedersen, L.H., 2005. Asset Pricing with Liquidity Risk. Journal of Financial Economics 77, 375-410.

Amihud, Y., Mendelson, H., 1980. Dealership Market: Market Making with Inventory. Journal of Financial Economics 8, 311-353.

Amihud, Y., Mendelson, H., 1986a. Asset Pricing and the Bid-Ask Spread. Journal of Financial Economics 17, 223-249.

Amihud, Y., Mendelson, H., 1986b. Liquidity and Stock Returns. Financial Analysts Journal $42,43-48$.

Amihud, Y., Mendelson, H., Lauterbach, B., 1997. Market Microstructure and Securities Values: Evidence from the Tel Aviv Exchange. Journal of Financial Economics 45, 365390.

Amihud, Y. Mendelson, H., Pedersen, L., 2005. Liquidity and Asset Prices. Foundations and Trends in Finance 1, 269-364.

Amihud, Y., 2002. Illiquidity and Stock Returns: Cross-section and Time-series Effects. Journal of Financial Markets 5, 31-56.

Barber, B.M., Odean, T., 2002. Online Investor: Do Slow Die First? Review of Financial Studies 15, 455-487.

Bekaert, G., Harvey, C.R., Lundblad, C., 2007. Liquidity and Expected Returns: Lessons from Emerging Markets. Review of Financial Studies 20, 1783-1831.

Ben-Rephael, A., Kadan, O., Wohl, A., 2008. The Diminishing Liquidity Premium. Working paper, available at SSRN: http://ssrn.com/abstract=1099829.

Berkman, H., Eleswarapu, V.R., 1998. Short-term Traders and Liquidity: a Test Using Bombay Stock Exchange Data. Journal of Financial Economics 47, 339-355.

Biais, B., Glosten, L., Spatt, C., 2005. Market Microstructure: a Survey of Micro Foundations, Empirical Results and Policy Implications. Journal of Financial Markets 8, 217-264. 
Bogle, J., 2005. The Mutual Fund Industry 60 Years Later: for Better or Worse? Financial Analysts Journal 61, 15-24.

Brennan, M.J., Subrahmanyam, A., 1996. Market Microstructure and Asset Pricing: on the Compensation for Illiquidity in Stock Returns. Journal of Financial Economics 41, 441464.

Brennan, M.J., Chordia, T., Subrahmanyam, A., 1998. Alternative Factor Specifications, Security Characteristics, and the Cross Section of Expected Stock Returns. Journal of Financial Economics 49, 345-373.

Brockman, P., Chung, D.Y., Perignon, C., 2009. Commonality in Liquidity: A Global Perspective. Journal of Financial and Quantitative Analysis 44, 851-882.

Brown, J.H., Crocker, D.K., Foerster, S.R., Trading Volume and Stock Investments. Financial Analysts Journal 65, 67-84.

Carhart, M., 1997. On Persistence in Mutual Fund Performance. Journal of Finance 52, 57-82.

Chakravarty, S., Panchapagesan, V., Wood, R., 2005. Did Decimalization Hurt Institutional Investors? Journal of Financial Markets 8, 400-420.

Chalmers, J.M.R., Kadlec, G.B., 1998. An Empirical Examination of the Amortized Spread. Journal of Financial Economics 48, 159-188.

Chan, H.W., Faff, R.W., 2005. Asset Pricing and the Illiquidity Premium. Financial Review $40,429-458$.

Chordia, T., Roll, R., Subrahmanyam, A., 2001. Market Liquidity and Trading Activity. Journal of Finance 56, 501-530.

Chordia, T., Subrahmanyam, A., Anshuman, V. R., 2001. Trading Activity and Expected Stock Returns. Journal of Financial Economics 59, 3-32.

Chordia, T., Roll, R., Subrahmanyam, A., 2009. Why has Trading Volume Increased? working paper, available at SSRN: http://ssrn.com/abstract=1364006.

Cochrane, J.H., 2005a. Asset Pricing Program Review: Liquidity, Trading and Asset Prices. NBER Reporter. 
Cochrane, J. H., 2005b. Asset Pricing. Princeton University Press: New Jersey.

Constantinindes, G., 1986. Capital Market Equilibrium with Transactions Costs. Journal of Political Economy 94, 842-862.

Cuthbertson, K., Nitzsche, D., O'Sullivan, N., 2008. Mutual Fund Performance: Skill or Luck? Journal of Empirical Finance 15, 613-634.

Daniel, K., Hirshleifer, D.A., Subrahmanyam, A., 1998. Investor Psychology and Security Market Under- and Over- reactions. Journal of Finance 53, 1839-1885.

Datar, V.T., Naik, N.Y., Radcliffe, R., 1998. Liquidity and Stock Returns: an Alternative Test. Journal of Financial Markets 1, 205-219.

Domowitz, I., 2002. Liquidity, Transaction Costs, and Re-intermediation in Electronic Markets. Journal of Financial Services Research 22, 141-157.

Easley, D., Hvidkjaer, S., O’Hara, M., 2002, Is Information Risk a Determinant of Asset Returns? Journal of Finance 57, 2185-2221.

Easley, D., Hvidkjaer, S., O'Hara, M., 2010. Factoring Information into Returns. Journal of Financial and Quantitative Analysis, forthcoming.

Fama, E.F., French, K.R., 1993. Common Risk Factors in the Returns on Stocks and Bonds. Journal of Financial Economics 33, 3-56.

Fama, E., MacBeth, J., 1973. Risk, Return, and Equilibrium: Empirical Tests. Journal of Political Economy 81, 607-636.

Fletcher, J., Kihanda, J., 2005, An Examination of Alternative CAPM-based Models in UK Stock Returns. Journal of Banking and Finance 29, 2995-3014.

French, K., The Cost of Active Investing. Journal of Finance 63, 1537-1573.

Gibbons, M.R., Ross, S.A., Shanken, J., 1989. A Test of the Efficiency of a Given Portfolio. Econometrica 57, 1121-1152.

Goyenko, R.Y., Holden, C.W., Trzcinka, C.A., 2009. Do Liquidity Measures Measure Liquidity? Journal of Financial Economics 2009, forthcoming. 
Goyenko, R.Y., Ukhov, A.D., 2009. Stock and Bond Market Liquidity: A Long-Run Empirical Analysis. Journal of Financial and Quantitative Analysis 44, 189-212.

Hasbrouck, J., 2005. Inferring Trading Costs from Daily Data: US Equities for 1962 to 2001. working paper, New York University.

Heaton, J., Lucas, D., 1995. Evaluating the Effects of Incomplete Markets on Risk Sharing and Asset Pricing. Journal of Political Economy 104, 443-497.

Heflin. F., Shaw, K.W., 2000. Blockholder Ownership and Market Liquidity. Journal of Financial and Quantitative Analysis 35, 621-633.

Jacoby, G., Fowler, D., Gottesman, A.A., 2000. The Capital Asset Pricing Model and the Liquidity Effect: a Theoretical Approach. Journal of Financial Markets 3, 69-81.

Jain, P.K., 2005. Financial Market Design and the Equity Premium: Electronic versus Floor Trading. Journal of Finance 60, 2955-2985.

Khan, W.A., Baker, H.K., Unlisted Trading Privileges, Liquidity and Stock Returns. Journal of Financial Research 16, 221-236.

Khandani, A.E., Lo, A.W., 2007. What Happened to the Quants in August 2007. Journal of Investment Management 5, 5-54.

Korajczyk, R.A., Sadka, R., Pricing the Commonality across Alternative Measures of Liquidity. Journal of Financial Economics 8, 45-72.

Kyle, A. S., 1985. Continuous Auctions and Insider Trading. Econometrica 53, 1315-1335.

Lee, C., 1993. Market Integration and Price Execution for NYSE-listed Securities. Journal of Finance 48, 1009-1038.

Liu, H., 2004. Optimal Consumption and Investment with Transaction Costs and Multiple Risky Assets. Journal of Finance 59, 289-338.

Liu, W., 2006. A Liquidity-augmented Capital Asset Pricing Model. Journal of Financial Economics 82, 631-671.

Loderer, C., Roth, L., 2005. The Pricing Discount for Limited Liquidity: Evidence from SWX Swiss Exchange and the Nasdaq. Journal of Empirical Finance 12, 239-268. 
Lo A., Mamaysky, H., Wang, J., 2004. Asset Prices and Trading Volume under Fixed Transactions Costs. Journal of Political Economy 112, 1054-1090.

Madhavan, A., Cheng, M., 1997. In Search of Liquidity: Block Trades in the Upstairs and Downstairs Markets. Review of Financial Studies 10, 175-204.

Merton, R.C., 1973. An Inter-temporal Capital Asset Pricing Model. Econometrica 41, 867887.

Naik, N., Yadav, P.K., 2004. Trading Costs of Public Investors with Obligatory and Voluntary Market-making: Evidence from Market Reforms. working paper, London Business School.

Nielsson, U., 2009. Stock Exchange Merger and Liquidity: the Case of Euronext. Journal of Financial Markets 12, 229-267.

Nguyen, D., Suchismita, M., Prakash, A., Ghosh, D.K., 2007. Liquidity Asset Pricing under the Three-moment CAPM Paradigm. Journal of Financial Research 30, 379-398.

O’Hara, M., 2003. Presidential Address: Liquidity and Price Discovery. Journal of Finance $58,1335-1354$.

O’Hara, M., 2007. Optimal Microstructures. European Financial Management 13, 825- 832.

O’Hara, M., Ye, M., 2009. Is Market Fragmentation Harming Market Quality? working paper, available at SSRN: http://ssrn.com/abstract=1356839.

Pastor, L., Stambaugh, R.F., 2003. Liquidity Risk and Expected Stock Returns. Journal of Political Economy 111, 642-685.

Peterson, M., Fialkowski, D., Posted versus Effective Spreads: Good Prices or Bad Quotes? Journal of Financial Economics 35, 269-292.

Shanken, J., 1992. On the Estimation of Beta Pricing Models. Review of Financial Studies 5, 1-34.

Stapledon, G.P., 1996. Institutional Shareholders and Corporate Governance. Oxford: Clarendon Press. 
Vayanos, D., 1998. Transaction Costs and Asset Prices: a Dynamic Equilibrium Model. Review of Financial Studies 11, 1-58.

Venkataraman, K., 2001. Automated Versus Floor Trading: an Analysis of Execution Costs on the Paris and New York Exchanges. Journal of Finance 56, 1445-1485.

Venkataraman, K., Waisburd, A.C., 2007. The Value of the Designated Market Maker. Journal of Financial and Quantitative Analysis 42, 735-758. 
TABLE 1

Performance and characteristics of decile portfolios constructed on the basis of the Return-to-Volume (RtoV) price impact ratio

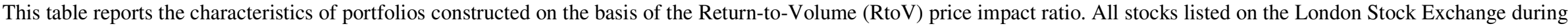

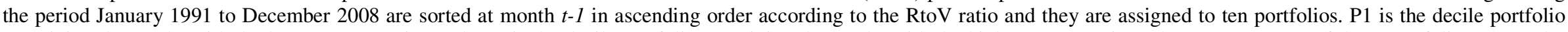

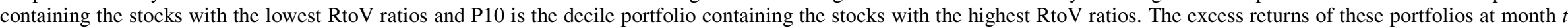

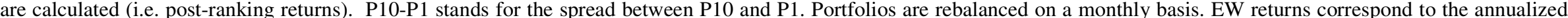

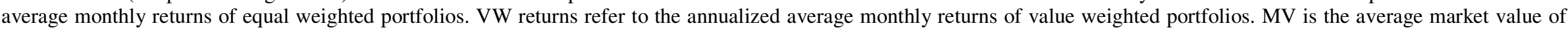

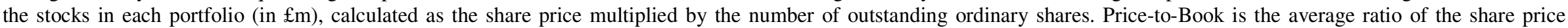

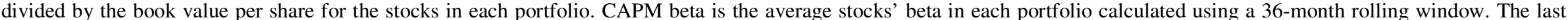
column reports values for $t$-tests referring to the null hypothesis of no difference in means between portfolios' P10 and P1 characteristics.

\begin{tabular}{|c|c|c|c|c|c|c|c|c|c|c|c|c|}
\hline & \multicolumn{12}{|c|}{ DECILE PORTFOLIO } \\
\hline & $\mathrm{P} 1$ & $\mathrm{P} 2$ & P3 & $\mathrm{P} 4$ & P5 & P6 & P7 & P8 & P9 & $\mathrm{P} 10$ & P10-P1 & $t$-test \\
\hline & \multicolumn{12}{|c|}{ Panel A. February 1991-December 2008} \\
\hline EW returns (\% p.a.) & 0.852 & 0.260 & 1.670 & 1.421 & 3.277 & 5.247 & 5.735 & 6.905 & 7.344 & 14.242 & 13.390 & 3.093 \\
\hline VW returns (\% p.a.) & -0.735 & -0.564 & 0.359 & -0.418 & 0.408 & 1.593 & 0.127 & 1.046 & 0.665 & 5.479 & 6.215 & 1.517 \\
\hline RtoV ratio $\left(\times 10^{6}\right)$ & 5.97E-04 & 2.19E-03 & $6.28 \mathrm{E}-03$ & $1.63 \mathrm{E}-02$ & $3.77 \mathrm{E}-02$ & $7.48 \mathrm{E}-02$ & $1.37 \mathrm{E}-01$ & $2.54 \mathrm{E}-01$ & $5.09 \mathrm{E}-01$ & 2.50 & 2.50 & 15.015 \\
\hline $\mathrm{MV}(£ \mathrm{~m})$ & 12005.541 & 2216.778 & 1028.539 & 588.152 & 366.601 & 258.182 & 187.943 & 136.944 & 101.645 & 64.412 & -11941.13 & -47.977 \\
\hline Price-to-Book & 3.414 & 3.300 & 3.437 & 3.458 & 3.368 & 3.343 & 3.203 & 2.902 & 2.813 & 2.542 & -0.872 & -14.784 \\
\hline \multirow[t]{2}{*}{ CAPM Beta } & 1.005 & 1.095 & 1.062 & 1.088 & 1.073 & 1.045 & 1.028 & 1.023 & 1.021 & 1.011 & 0.006 & 0.290 \\
\hline & \multicolumn{12}{|c|}{ Panel B. February 1991-December 1999} \\
\hline EW returns (\% p.a.) & 7.094 & 4.563 & 5.628 & 9.242 & 9.016 & 9.050 & 12.080 & 13.727 & 14.641 & 20.499 & 13.405 & 2.151 \\
\hline VW returns (\% p.a.) & 6.754 & 5.470 & 4.459 & 7.019 & 7.078 & 6.889 & 8.071 & 7.477 & 8.341 & 16.490 & 9.736 & 1.717 \\
\hline RtoV ratio $\left(\mathrm{x} 10^{6}\right)$ & 7.99E-04 & $2.32 \mathrm{E}-03$ & $5.34 \mathrm{E}-03$ & $1.11 \mathrm{E}-02$ & 2.14E-02 & 3.97E-02 & $7.26 \mathrm{E}-02$ & $1.32 \mathrm{E}-01$ & $2.60 \mathrm{E}-01$ & 1.15 & 1.15 & 16.46 \\
\hline $\mathrm{MV}(£ \mathrm{~m})$ & 9514.635 & 2573.908 & 1300.101 & 776.216 & 496.561 & 351.341 & 255.295 & 187.895 & 140.512 & 86.815 & -9427.820 & -33.393 \\
\hline Price-to-Book & 3.202 & 3.146 & 3.232 & 3.263 & 3.369 & 3.494 & 3.336 & 2.998 & 2.907 & 2.389 & -0.813 & -10.097 \\
\hline \multirow[t]{2}{*}{ CAPM Beta } & 1.000 & 1.043 & 1.047 & 1.028 & 1.020 & 1.020 & 0.995 & 1.000 & 1.005 & 1.030 & 0.030 & 0.964 \\
\hline & \multicolumn{12}{|c|}{ Panel C. January 2000-December 2008} \\
\hline EW returns (\% p.a.) & -5.332 & -4.003 & -2.251 & -6.328 & -2.408 & 1.479 & -0.552 & 0.146 & 0.115 & 8.043 & 13.375 & 2.213 \\
\hline VW returns (\% p.a.) & -8.155 & -6.542 & -3.703 & -7.786 & -6.201 & -3.654 & -7.744 & -5.325 & -6.940 & -5.429 & 2.726 & 0.461 \\
\hline RtoV ratio $\left(\times 10^{6}\right)$ & 3.97E-04 & 2.07E-03 & $7.21 \mathrm{E}-03$ & 2.13E-02 & 5.39E-02 & $1.09 \mathrm{E}-01$ & 2.02E-01 & 3.74E-01 & 7.56E-01 & 3.84 & 3.84 & 14.37 \\
\hline $\mathrm{MV}(£ \mathrm{~m})$ & 14473.384 & 1862.954 & 759.491 & 401.829 & 237.845 & 165.885 & 121.214 & 86.464 & 63.137 & 42.217 & -14431.16 & -63.304 \\
\hline Price-to-Book & 3.625 & 3.452 & 3.640 & 3.651 & 3.367 & 3.192 & 3.071 & 2.807 & 2.719 & 2.694 & -0.931 & -10.799 \\
\hline CAPM Beta & 1.009 & 1.146 & 1.077 & 1.148 & 1.125 & 1.069 & 1.061 & 1.046 & 1.037 & 0.992 & -0.017 & -0.585 \\
\hline
\end{tabular}


TABLE 2

Performance and characteristics of decile portfolios constructed on the basis of the Return-to-Turnover Rate (RtoTR) price impact ratio

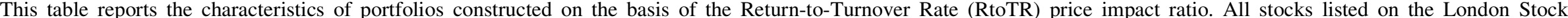

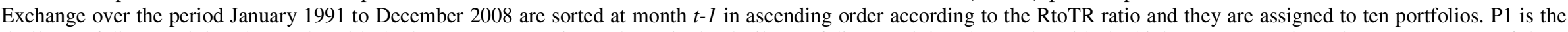

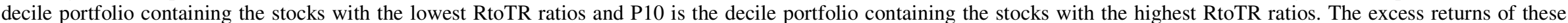

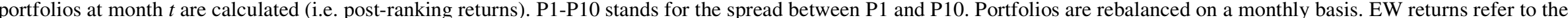

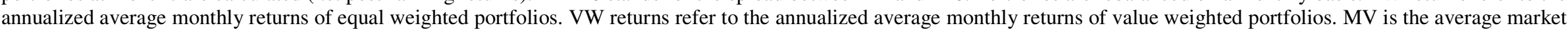

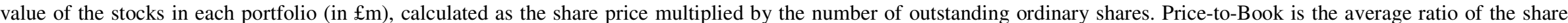

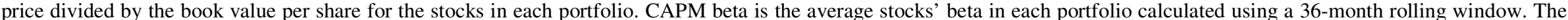
last column reports values for $t$-tests referring to the null hypothesis of no difference in means between portfolios' P1 and P10 characteristics.

\begin{tabular}{|c|c|c|c|c|c|c|c|c|c|c|c|c|}
\hline & \multicolumn{12}{|c|}{ DECILE PORTFOLIO } \\
\hline & $\mathrm{P} 1$ & $\mathrm{P} 2$ & P3 & $\mathrm{P} 4$ & P5 & P6 & $\mathrm{P} 7$ & P8 & $\mathrm{P9}$ & $\mathrm{P} 10$ & P1-P10 & $t$-test \\
\hline & \multicolumn{12}{|c|}{ Panel A. February 1991-December 2008} \\
\hline EW returns (\% p.a.) & 13.902 & 6.357 & 8.220 & 2.886 & 6.032 & 4.659 & 3.080 & 0.645 & 2.556 & -1.493 & 15.395 & 5.156 \\
\hline VW returns (\% p.a.) & 6.551 & 1.842 & 1.939 & -2.538 & -3.239 & -1.684 & -5.087 & -6.487 & -7.814 & -5.918 & 12.469 & 3.896 \\
\hline RtoTR ratio & 1.441 & 2.899 & 4.131 & 5.598 & 7.522 & 10.203 & 14.200 & 20.968 & 35.425 & 120.436 & -118.996 & -42.730 \\
\hline $\mathrm{MV}(£ \mathrm{~m})$ & 2719.871 & 3499.827 & 3345.892 & 2313.492 & 1789.928 & 1231.784 & 835.937 & 579.423 & 386.894 & 253.512 & 2466.359 & 31.029 \\
\hline Price-to-Book & 3.660 & 3.315 & 3.219 & 3.246 & 3.281 & 3.203 & 3.083 & 2.948 & 2.956 & 2.875 & 0.785 & 9.966 \\
\hline \multirow[t]{2}{*}{ CAPM Beta } & 0.952 & 1.023 & 1.053 & 1.081 & 1.066 & 1.070 & 1.060 & 1.047 & 1.034 & 1.073 & -0.122 & -6.986 \\
\hline & \multicolumn{12}{|c|}{ Panel B. February 1991-December 1999} \\
\hline EW returns (\% p.a.) & 22.920 & 13.347 & 11.892 & 5.688 & 12.028 & 7.488 & 9.373 & 7.606 & 9.705 & 5.345 & 17.575 & 4.361 \\
\hline VW returns (\% p.a.) & 14.922 & 10.565 & 7.103 & 5.612 & 6.898 & 2.775 & 1.752 & 2.388 & 1.996 & 3.873 & 11.050 & 2.957 \\
\hline RtoTR ratio & 1.435 & 3.104 & 4.467 & 5.838 & 7.447 & 9.648 & 12.951 & 18.734 & 31.132 & 103.487 & -102.053 & -33.174 \\
\hline $\mathrm{MV}(£ \mathrm{~m})$ & 2109.883 & 2242.825 & 2292.215 & 2114.469 & 2246.136 & 1808.805 & 1224.806 & 773.567 & 530.643 & 342.754 & 1767.130 & 24.756 \\
\hline Price-to-Book & 3.935 & 3.231 & 3.156 & 3.076 & 3.181 & 3.137 & 3.083 & 2.935 & 2.919 & 2.759 & 1.175 & 14.296 \\
\hline \multirow[t]{2}{*}{ CAPM Beta } & 0.965 & 0.981 & 1.006 & 1.031 & 1.031 & 1.016 & 1.030 & 1.027 & 1.032 & 1.071 & -0.106 & -5.249 \\
\hline & \multicolumn{12}{|c|}{ Panel C. January 2000-December 2008} \\
\hline EW returns (\% p.a.) & 4.968 & -0.568 & 4.582 & 0.110 & 0.093 & 1.856 & -3.155 & -6.251 & -4.527 & -8.267 & 13.235 & 2.999 \\
\hline VW returns (\% p.a.) & -1.743 & -6.800 & -3.178 & -10.612 & -13.282 & -6.103 & -11.862 & -15.280 & -17.533 & -15.617 & 13.875 & 2.668 \\
\hline RtoTR ratio & 1.447 & 2.696 & 3.797 & 5.360 & 7.597 & 10.752 & 15.438 & 23.181 & 39.678 & 137.228 & -135.781 & -33.633 \\
\hline $\mathrm{MV}(£ \mathrm{~m})$ & 3324.211 & 4745.190 & 4389.812 & 2510.672 & 1337.945 & 660.105 & 450.668 & 387.078 & 244.477 & 165.096 & 3159.115 & 29.928 \\
\hline Price-to-Book & 3.388 & 3.398 & 3.281 & 3.414 & 3.379 & 3.268 & 3.082 & 2.962 & 2.992 & 2.990 & 0.398 & 3.222 \\
\hline CAPM Beta & 0.938 & 1.065 & 1.099 & 1.132 & 1.101 & 1.123 & 1.089 & 1.067 & 1.036 & 1.075 & -0.137 & -4.835 \\
\hline
\end{tabular}




\section{TABLE 3}

\section{Alphas of value-weighted portfolios sorted by the Return-to-Volume (RtoV) price impact ratio}

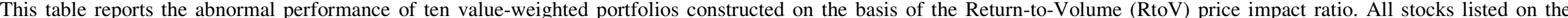

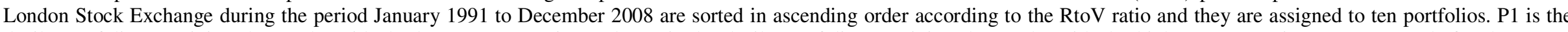

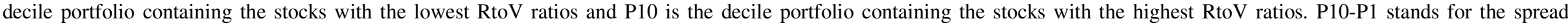

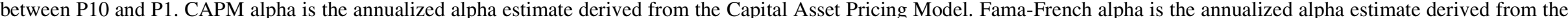

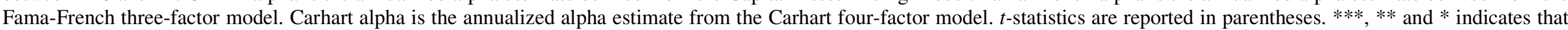

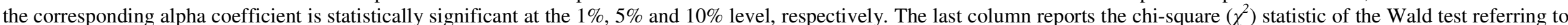
the null hypothesis that the ten portfolios' alphas are jointly equal to zero; $\mathrm{p}$-values are reported below the statistic.

\begin{tabular}{|c|c|c|c|c|c|c|c|c|c|c|c|c|}
\hline & \multicolumn{12}{|c|}{ "DECILE PORTFOLIO } \\
\hline & $\mathrm{P} 1$ & $\mathrm{P} 2$ & P3 & $\mathrm{P} 4$ & P5 & P6 & $\mathrm{P} 7$ & P8 & P9 & $\mathrm{P} 10$ & $\mathrm{P} 10-\mathrm{P} 1$ & Chi-sq. \\
\hline & \multicolumn{12}{|c|}{ Panel A: February 1991-December 2008} \\
\hline CAPM alpha (\% p.a.) & $\begin{array}{c}0.90 \\
(1.27)\end{array}$ & $\begin{array}{c}1.37 \\
(0.85)\end{array}$ & $\begin{array}{c}2.27 \\
(1.16)\end{array}$ & $\begin{array}{c}1.64 \\
(0.72)\end{array}$ & $\begin{array}{c}2.51 \\
(1.04)\end{array}$ & $\begin{array}{c}3.54 \\
(1.34)\end{array}$ & $\begin{array}{c}2.05 \\
(0.78)\end{array}$ & $\begin{array}{c}2.85 \\
(0.91)\end{array}$ & $\begin{array}{c}2.60 \\
(0.84)\end{array}$ & $\begin{array}{l}7.49 \\
(2.10)^{* * * *}\end{array}$ & $\begin{array}{c}6.58 \\
(1.64)\end{array}$ & $\begin{array}{l}19.29 \\
(0.037)\end{array}$ \\
\hline Fama-French alpha (\% p.a.) & $\begin{array}{c}1.49 \\
(3.19)^{* * *}\end{array}$ & $\begin{array}{c}0.18 \\
(0.15)\end{array}$ & $\begin{array}{c}0.54 \\
(0.45)\end{array}$ & $\begin{array}{l}-0.19 \\
(-0.12)\end{array}$ & $\begin{array}{c}0.70 \\
(0.39)\end{array}$ & $\begin{array}{c}1.62 \\
(0.71)\end{array}$ & $\begin{array}{c}0.33 \\
(0.14)\end{array}$ & $\begin{array}{c}0.47 \\
(0.20)\end{array}$ & $\begin{array}{c}0.58 \\
(0.20)\end{array}$ & $\begin{array}{c}5.33 \\
(1.62)\end{array}$ & $\begin{array}{c}3.83 \\
(1.13)\end{array}$ & $\begin{array}{l}20.12 \\
(0.028)\end{array}$ \\
\hline \multirow[t]{2}{*}{ Carhart alpha (\% p.a.) } & $\begin{array}{c}1.54 \\
(3.19)^{* * *}\end{array}$ & $\begin{array}{c}0.05 \\
(0.04)\end{array}$ & $\begin{array}{c}-0.02 \\
(-0.02)\end{array}$ & $\begin{array}{c}0.08 \\
(0.04)\end{array}$ & $\begin{array}{c}0.93 \\
(0.50)\end{array}$ & $\begin{array}{c}1.22 \\
(0.50)\end{array}$ & $\begin{array}{c}0.36 \\
(0.15)\end{array}$ & $\begin{array}{c}0.61 \\
(0.24)\end{array}$ & $\begin{array}{c}1.99 \\
(0.65)\end{array}$ & $\begin{array}{c}5.38 \\
(1.49)\end{array}$ & $\begin{array}{c}3.84 \\
(1.02)\end{array}$ & $\begin{array}{l}17.82 \\
(0.058)\end{array}$ \\
\hline & \multicolumn{12}{|c|}{ Panel B: February 1991-December 1999} \\
\hline CAPM alpha (\% p.a.) & $\begin{array}{c}1.58 \\
(1.33)\end{array}$ & $\begin{array}{c}-0.19 \\
(-0.11)\end{array}$ & $\begin{array}{l}-1.38 \\
(-0.63)\end{array}$ & $\begin{array}{c}0.84 \\
(0.30)\end{array}$ & $\begin{array}{c}0.47 \\
(0.18)\end{array}$ & $\begin{array}{c}0.93 \\
(0.27)\end{array}$ & $\begin{array}{c}1.97 \\
(0.61)\end{array}$ & $\begin{array}{c}1.99 \\
(0.50)\end{array}$ & $\begin{array}{c}2.25 \\
(0.57)\end{array}$ & $\begin{array}{l}10.46 \\
(2.18)^{* *}\end{array}$ & $\begin{array}{c}8.88 \\
(1.57)\end{array}$ & $\begin{array}{l}22.73 \\
(0.012)\end{array}$ \\
\hline Fama-French alpha (\% p.a.) & $\begin{array}{c}1.23 \\
(2.20)^{* *}\end{array}$ & $\begin{array}{c}0.60 \\
(0.05)\end{array}$ & $\begin{array}{c}-0.76 \\
(-0.49)\end{array}$ & $\begin{array}{c}1.62 \\
(0.76)\end{array}$ & $\begin{array}{c}1.15 \\
(0.79)\end{array}$ & $\begin{array}{c}1.82 \\
(0.54)\end{array}$ & $\begin{array}{c}2.76 \\
(1.03)\end{array}$ & $\begin{array}{c}2.99 \\
(0.98)\end{array}$ & $\begin{array}{c}3.27 \\
(1.09)\end{array}$ & $\begin{array}{l}11.41 \\
(2.73) * * *\end{array}$ & $\begin{array}{l}10.19 \\
(2.33)^{* *}\end{array}$ & $\begin{array}{l}24.08 \\
(0.007)\end{array}$ \\
\hline \multirow[t]{2}{*}{ Carhart alpha (\% p.a.) } & $\begin{array}{c}1.19 \\
(1.67)\end{array}$ & $\begin{array}{l}-1.07 \\
(-0.73)\end{array}$ & $\begin{array}{l}-0.71 \\
(-0.45)\end{array}$ & $\begin{array}{c}2.94 \\
(1.25)\end{array}$ & $\begin{array}{c}2.43 \\
(1.64)\end{array}$ & $\begin{array}{c}1.76 \\
(0.49)\end{array}$ & $\begin{array}{c}3.36 \\
(1.22)\end{array}$ & $\begin{array}{c}3.88 \\
(1.14)\end{array}$ & $\begin{array}{c}4.94 \\
(1.60)\end{array}$ & $\begin{array}{l}12.95 \\
(2.70)^{* * *}\end{array}$ & $\begin{array}{l}11.76 \\
(2.30)^{* *}\end{array}$ & $\begin{array}{l}26.17 \\
(0.003)\end{array}$ \\
\hline & \multicolumn{12}{|c|}{ Panel C. January 2000-December 2008} \\
\hline CAPM alpha (\% p.a.) & $\begin{array}{c}0.33 \\
(0.47)\end{array}$ & $\begin{array}{c}4.17 \\
(1.56)\end{array}$ & $\begin{array}{c}6.65 \\
(2.16)^{* *}\end{array}$ & $\begin{array}{c}3.38 \\
(0.95)\end{array}$ & $\begin{array}{c}4.82 \\
(1.23)\end{array}$ & $\begin{array}{c}6.86 \\
(1.66)\end{array}$ & $\begin{array}{c}2.19 \\
(0.52)\end{array}$ & $\begin{array}{c}4.40 \\
(0.92)\end{array}$ & $\begin{array}{c}3.18 \\
(0.67)\end{array}$ & $\begin{array}{c}5.27 \\
(1.02)\end{array}$ & $\begin{array}{c}4.94 \\
(0.88)\end{array}$ & $\begin{array}{l}23.38 \\
(0.009)\end{array}$ \\
\hline Fama-French alpha (\% p.a.) & $\begin{array}{c}1.42 \\
(3.10)^{* * *}\end{array}$ & $\begin{array}{l}-0.60 \\
(-0.47)\end{array}$ & $\begin{array}{c}1.07 \\
(0.62)\end{array}$ & $\begin{array}{c}-1.81 \\
(-0.84)\end{array}$ & $\begin{array}{c}-0.76 \\
(-0.24)\end{array}$ & $\begin{array}{c}1.95 \\
(0.62)\end{array}$ & $\begin{array}{c}-2.54 \\
(-0.71)\end{array}$ & $\begin{array}{c}-2.44 \\
(-0.68)\end{array}$ & $\begin{array}{l}-2.28 \\
(-0.47)\end{array}$ & $\begin{array}{c}-0.85 \\
(-0.21)\end{array}$ & $\begin{array}{c}-2.27 \\
(-0.54)\end{array}$ & $\begin{array}{l}19.24 \\
(0.037)\end{array}$ \\
\hline Carhart alpha (\% p.a.) & $\begin{array}{c}1.54 \\
(3.49)^{* * *}\end{array}$ & $\begin{array}{c}-0.29 \\
(-0.23)\end{array}$ & $\begin{array}{c}0.58 \\
(0.34)\end{array}$ & $\begin{array}{c}-1.92 \\
(-0.90)\end{array}$ & $\begin{array}{c}-0.78 \\
(-0.24)\end{array}$ & $\begin{array}{c}1.50 \\
(0.47)\end{array}$ & $\begin{array}{l}-2.68 \\
(-0.71)\end{array}$ & $\begin{array}{l}-2.51 \\
(-0.70)\end{array}$ & $\begin{array}{l}-1.30 \\
(-0.26)\end{array}$ & $\begin{array}{l}-1.26 \\
(-0.29)\end{array}$ & $\begin{array}{l}-2.80 \\
(-0.63)\end{array}$ & $\begin{array}{l}19.29 \\
(0.037)\end{array}$ \\
\hline
\end{tabular}




\section{TABLE 4}

\section{Alphas of value-weighted portfolios sorted by the Return-to-Turnover Rate (RtoTR) price impact ratio}

This table reports the abnormal performance of ten value-weighted portfolios constructed on the basis of the Return-to-Turnover Rate (RtoTR) price impact ratio. All stocks listed

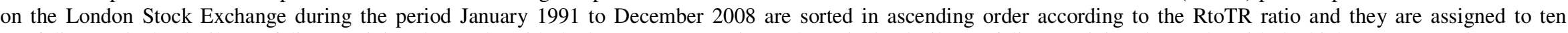
portfolios. P1 is the decile portfolio containing the stocks with the lowest RtoTR ratios and P10 is the decile portfolio containing the stocks with the highest RtoTR ratios. P1-P10

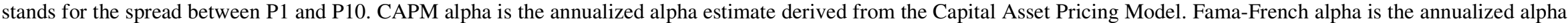

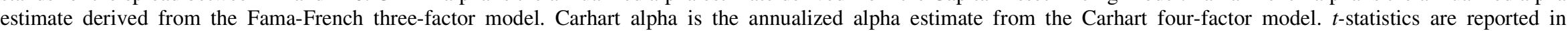

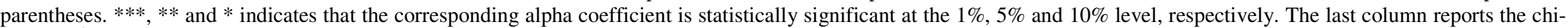
square $\left(\chi^{2}\right)$ statistic of the Wald test referring to the null hypothesis that the ten portfolios' alphas are jointly equal to zero; p-values are reported below the statistic.

\begin{tabular}{|c|c|c|c|c|c|c|c|c|c|c|c|c|}
\hline & \multicolumn{12}{|c|}{ DECILE PORTFOLIO } \\
\hline & $\mathrm{P} 1$ & $\mathrm{P} 2$ & P3 & $\mathrm{P} 4$ & P5 & P6 & P7 & P8 & P9 & $\mathrm{P} 10$ & P1-P10 & Chi-sq. \\
\hline & \multicolumn{12}{|c|}{ Panel A. February 1991-December 2008} \\
\hline CAPM alpha (\% p.a.) & $\begin{array}{l}8.30 \\
(4.46)^{* * *}\end{array}$ & $\begin{array}{l}3.48 \\
(2.31)^{* *}\end{array}$ & $\begin{array}{l}3.66 \\
(1.98)^{* *}\end{array}$ & $\begin{array}{c}-0.70 \\
(-0.45)\end{array}$ & $\begin{array}{l}-1.46 \\
(-0.59)\end{array}$ & $\begin{array}{c}0.25 \\
(0.10)\end{array}$ & $\begin{array}{l}-3.08 \\
(-1.07)\end{array}$ & $\begin{array}{l}-4.53 \\
(-1.53)\end{array}$ & $\begin{array}{l}-5.60 \\
(-1.44)\end{array}$ & $\begin{array}{l}-3.89 \\
(-1.32)\end{array}$ & $\begin{array}{l}12.20 \\
(3.65)^{* * *}\end{array}$ & $\begin{array}{l}42.23 \\
(0.00)\end{array}$ \\
\hline Fama-French alpha (\% p.a.) & $\begin{array}{l}7.79 \\
(4.39) * * *\end{array}$ & $\begin{array}{c}3.10 \\
(2.03)^{*}\end{array}$ & $\begin{array}{l}3.87 \\
(2.12)^{* *}\end{array}$ & $\begin{array}{c}-0.72 \\
(-0.44)\end{array}$ & $\begin{array}{c}-1.73 \\
(-0.71)\end{array}$ & $\begin{array}{c}-0.31 \\
(-0.12)\end{array}$ & $\begin{array}{l}-3.82 \\
(-1.52)\end{array}$ & $\begin{array}{l}-5.80 \\
(-2.08)^{* *}\end{array}$ & $\begin{array}{c}-7.74 \\
(-2.45)^{* *}\end{array}$ & $\begin{array}{l}-5.78 \\
(-2.25)^{* *}\end{array}$ & $\begin{array}{l}13.58 \\
(4.22)^{* * * *}\end{array}$ & $\begin{array}{l}42.30 \\
(0.00)\end{array}$ \\
\hline \multirow[t]{2}{*}{ Carhart alpha (\% p.a.) } & $\begin{array}{l}6.53 \\
(3.93)^{* * *}\end{array}$ & $\begin{array}{l}3.07 \\
(1.91)^{*}\end{array}$ & $\begin{array}{l}3.41 \\
(2.03)^{* *}\end{array}$ & $\begin{array}{c}-0.99 \\
(-0.63) \\
\end{array}$ & $\begin{array}{l}-1.75 \\
(-0.72)\end{array}$ & $\begin{array}{c}0.88 \\
(0.34)\end{array}$ & $\begin{array}{c}-4.22 \\
(-1.62) \\
\end{array}$ & $\begin{array}{l}-5.97 \\
(-1.96) * *\end{array}$ & $\begin{array}{c}-6.85 \\
(-2.16)^{* *}\end{array}$ & $\begin{array}{l}-6.85 \\
(-2.26)^{* *}\end{array}$ & $\begin{array}{l}13.38 \\
(3.77) * * *\end{array}$ & $\begin{array}{c}33.22 \\
(0.00)\end{array}$ \\
\hline & \multicolumn{12}{|c|}{ Panel B. February 1991-December 1999} \\
\hline CAPM alpha (\% p.a.) & $\begin{array}{l}8.87 \\
(6.17)^{* * *}\end{array}$ & $\begin{array}{c}5.55 \\
(2.34)^{* *}\end{array}$ & $\begin{array}{c}1.22 \\
(0.68)\end{array}$ & $\begin{array}{c}0.01 \\
(-0.01)\end{array}$ & $\begin{array}{c}1.85 \\
(0.93)\end{array}$ & $\begin{array}{c}2.66 \\
(-1.20)\end{array}$ & $\begin{array}{l}-4.16 \\
(-2.03) * *\end{array}$ & $\begin{array}{c}-2.62 \\
(-0.98)\end{array}$ & $\begin{array}{c}-4.33 \\
(-0.84)\end{array}$ & $\begin{array}{c}-2.67 \\
(-0.75)\end{array}$ & $\begin{array}{l}11.54 \\
(3.19)\end{array}$ & $\begin{array}{l}68.31 \\
(0.000)\end{array}$ \\
\hline Fama-French alpha (\% p.a.) & $\begin{array}{l}8.92 \\
(6.16)^{* * *}\end{array}$ & $\begin{array}{c}5.71 \\
(2.37)^{* *}\end{array}$ & $\begin{array}{c}1.26 \\
(0.73)\end{array}$ & $\begin{array}{c}0.16 \\
(0.10)\end{array}$ & $\begin{array}{c}1.60 \\
(0.87)\end{array}$ & $\begin{array}{c}-2.67 \\
(-1.21)\end{array}$ & $\begin{array}{l}-4.29 \\
(-2.11)^{* *}\end{array}$ & $\begin{array}{c}-2.42 \\
(-0.98)\end{array}$ & $\begin{array}{c}-3.45 \\
(-0.95)\end{array}$ & $\begin{array}{l}-1.95 \\
(-0.74)\end{array}$ & $\begin{array}{l}10.87 \\
(3.82)^{* * *}\end{array}$ & $\begin{array}{l}65.07 \\
(0.000)\end{array}$ \\
\hline \multirow[t]{2}{*}{ Carhart alpha (\% p.a.) } & $\begin{array}{l}6.67 \\
(4.83)^{* * *}\end{array}$ & $\begin{array}{c}6.21 \\
(2.44)^{* *}\end{array}$ & $\begin{array}{c}-0.49 \\
(-0.33)\end{array}$ & $\begin{array}{c}-0.32 \\
(-0.20)\end{array}$ & $\begin{array}{c}2.34 \\
(1.24)\end{array}$ & $\begin{array}{l}-1.82 \\
(-0.86)\end{array}$ & $\begin{array}{c}-3.84 \\
(-1.78)^{*}\end{array}$ & $\begin{array}{l}-1.49 \\
(-0.52)\end{array}$ & $\begin{array}{c}-2.39 \\
(-0.63)\end{array}$ & $\begin{array}{l}-2.66 \\
(-1.01)\end{array}$ & $\begin{array}{l}9.33 \\
(3.11)^{* * *}\end{array}$ & $\begin{array}{l}39.99 \\
(0.000)\end{array}$ \\
\hline & \multicolumn{12}{|c|}{ Panel C. January 2000-December 2008} \\
\hline CAPM alpha (\% p.a.) & $\begin{array}{l}6.65 \\
(2.04)^{* *}\end{array}$ & $\begin{array}{c}1.83 \\
(0.95)\end{array}$ & $\begin{array}{l}5.28 \\
(2.02)^{* *}\end{array}$ & $\begin{array}{c}-0.83 \\
(-0.30)\end{array}$ & $\begin{array}{l}-3.42 \\
(-0.87)\end{array}$ & $\begin{array}{c}4.94 \\
(1.22)\end{array}$ & $\begin{array}{c}-5.36 \\
(-0.16)\end{array}$ & $\begin{array}{l}-3.65 \\
(-0.74)\end{array}$ & $\begin{array}{l}-5.18 \\
(-0.83)\end{array}$ & $\begin{array}{l}-5.36 \\
(-1.04)\end{array}$ & $\begin{array}{l}12.01 \\
(2.12)^{* *}\end{array}$ & $\begin{array}{l}20.92 \\
(0.022)\end{array}$ \\
\hline Fama-French alpha (\% p.a.) & $\begin{array}{c}3.82 \\
(1.36)\end{array}$ & $\begin{array}{c}-0.14 \\
(-0.08)\end{array}$ & $\begin{array}{l}6.86 \\
(3.09) * * *\end{array}$ & $\begin{array}{c}-0.20 \\
(-0.06)\end{array}$ & $\begin{array}{c}-6.03 \\
(-1.65)\end{array}$ & $\begin{array}{c}2.87 \\
(0.72)\end{array}$ & $\begin{array}{l}-4.38 \\
(-1.12)\end{array}$ & $\begin{array}{l}-8.48 \\
(-1.82)^{*}\end{array}$ & $\begin{array}{l}-12.02 \\
(-2.42)^{* *}\end{array}$ & $\begin{array}{l}-11.16 \\
(-2.46)^{* *}\end{array}$ & $\begin{array}{l}14.98 \\
(2.58) * * *\end{array}$ & $\begin{array}{l}27.26 \\
(0.002)\end{array}$ \\
\hline Carhart alpha (\% p.a.) & $\begin{array}{c}3.46 \\
(1.26)\end{array}$ & $\begin{array}{c}-0.20 \\
(-0.11)\end{array}$ & $\begin{array}{l}6.82 \\
(3.06) * * *\end{array}$ & $\begin{array}{c}-0.46 \\
(-0.16)\end{array}$ & $\begin{array}{c}-6.13 \\
(-1.64)\end{array}$ & $\begin{array}{c}3.87 \\
(0.96)\end{array}$ & $\begin{array}{l}-4.79 \\
(-1.15)\end{array}$ & $\begin{array}{l}-8.94 \\
(-1.91)^{*}\end{array}$ & $\begin{array}{l}-11.34 \\
(-2.36)^{* *}\end{array}$ & $\begin{array}{l}-11.88 \\
(-2.42)^{* * *}\end{array}$ & $\begin{array}{l}15.34 \\
(2.61)^{* * *}\end{array}$ & $\begin{array}{l}26.25 \\
(0.003)\end{array}$ \\
\hline
\end{tabular}




\section{TABLE 5}

Alphas of equal-weighted portfolios sorted by the Return-to-Turnover Rate (RtoTR) price impact ratio

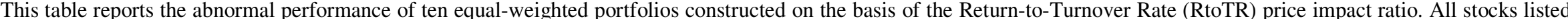

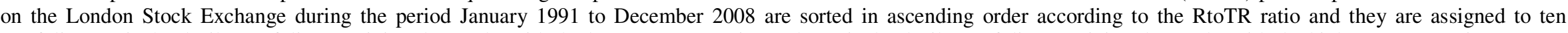

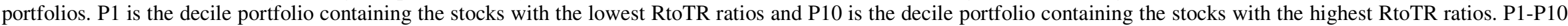

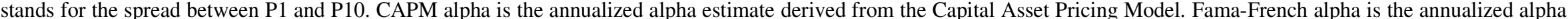

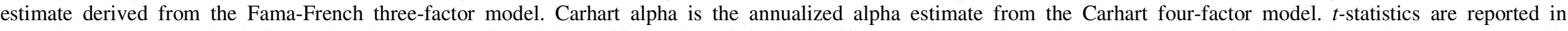

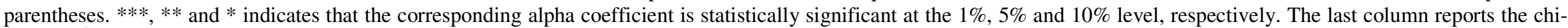
square $\left(\chi^{2}\right)$ statistic of the Wald test referring to the null hypothesis that the ten portfolios' alphas are jointly equal to zero; p-values are reported below the statistic.

\begin{tabular}{|c|c|c|c|c|c|c|c|c|c|c|c|c|}
\hline & \multicolumn{12}{|c|}{ DECILE PORTFOLIO } \\
\hline & P1 & $\mathrm{P} 2$ & P3 & $\mathrm{P} 4$ & P5 & P6 & P7 & P8 & P9 & $\mathrm{P} 10$ & P1-P10 & Chi-sq. \\
\hline & \multicolumn{12}{|c|}{ Panel A. February 1991-December 2008} \\
\hline CAPM alpha (\% p.a.) & $\begin{array}{l}16.62 \\
(5.61)^{* * *}\end{array}$ & $\begin{array}{c}8.10 \\
(3.92)^{* * *}\end{array}$ & $\begin{array}{l}10.15 \\
(4.22)^{* * *}\end{array}$ & $\begin{array}{c}4.89 \\
(1.85)^{*}\end{array}$ & $\begin{array}{l}8.03 \\
(2.96)^{* * *}\end{array}$ & $\begin{array}{l}6.56 \\
(2.24)^{* *}\end{array}$ & $\begin{array}{c}5.09 \\
(1.47)\end{array}$ & $\begin{array}{c}2.61 \\
(0.88)\end{array}$ & $\begin{array}{c}4.57 \\
(1.43)\end{array}$ & $\begin{array}{c}0.62 \\
(0.15)\end{array}$ & $\begin{array}{l}15.00 \\
(4.14)^{* * *}\end{array}$ & $\begin{array}{l}67.94 \\
(0.000)\end{array}$ \\
\hline Fama-French alpha (\% p.a.) & $\begin{array}{l}14.14 \\
(5.90)^{* * *}\end{array}$ & $\begin{array}{c}6.51 \\
(4.11)^{* * *}\end{array}$ & $\begin{array}{l}8.46 \\
(4.73)^{* * * *}\end{array}$ & $\begin{array}{c}3.06 \\
(1.73)^{*}\end{array}$ & $\begin{array}{l}6.43 \\
(3.38)^{* * * *}\end{array}$ & $\begin{array}{l}4.66 \\
(2.22)^{* *}\end{array}$ & $\begin{array}{c}3.13 \\
(1.18)\end{array}$ & $\begin{array}{c}0.64 \\
(0.28)\end{array}$ & $\begin{array}{c}2.51 \\
(1.05)\end{array}$ & $\begin{array}{l}-1.85 \\
(-0.56)\end{array}$ & $\begin{array}{l}15.99 \\
(4.84)^{* * *}\end{array}$ & $\begin{array}{l}81.81 \\
(0.000)\end{array}$ \\
\hline \multirow[t]{2}{*}{ Carhart alpha (\% p.a.) } & $\begin{array}{l}12.69 \\
(6.31)^{* * *}\end{array}$ & $\begin{array}{l}5.76 \\
(3.66)^{* * *}\end{array}$ & $\begin{array}{l}7.98 \\
(4.73)^{* * * *}\end{array}$ & $\begin{array}{c}2.82 \\
(1.53)\end{array}$ & $\begin{array}{l}6.18 \\
(3.03)^{* * *}\end{array}$ & $\begin{array}{l}4.54 \\
(2.01)^{* *}\end{array}$ & $\begin{array}{c}3.79 \\
(1.33)\end{array}$ & $\begin{array}{c}1.41 \\
(0.57)\end{array}$ & $\begin{array}{c}2.97 \\
(1.20)\end{array}$ & $\begin{array}{l}-1.84 \\
(-0.52)\end{array}$ & $\begin{array}{l}14.53 \\
(4.26)^{* * *}\end{array}$ & $\begin{array}{l}80.13 \\
(0.000)\end{array}$ \\
\hline & \multicolumn{12}{|c|}{ Panel B. February 1991-December 1999} \\
\hline CAPM alpha (\% p.a.) & $\begin{array}{l}17.03 \\
(5.80)^{* * *}\end{array}$ & $\begin{array}{c}7.81 \\
(3.20)^{* * *}\end{array}$ & $\begin{array}{l}5.94 \\
(2.02)^{* *}\end{array}$ & $\begin{array}{c}-0.44 \\
(-0.14)\end{array}$ & $\begin{array}{l}5.82 \\
(1.97)^{* *}\end{array}$ & $\begin{array}{c}1.77 \\
(0.53)\end{array}$ & $\begin{array}{c}3.17 \\
(0.86)\end{array}$ & $\begin{array}{c}1.65 \\
(0.44)\end{array}$ & $\begin{array}{c}3.27 \\
(0.73)\end{array}$ & $\begin{array}{c}-1.41 \\
(-0.24)\end{array}$ & $\begin{array}{l}18.44 \\
(4.17)^{* * *}\end{array}$ & $\begin{array}{l}127.64 \\
(0.000)\end{array}$ \\
\hline Fama-French alpha (\% p.a.) & $\begin{array}{l}17.45 \\
(7.06)^{* * *}\end{array}$ & $\begin{array}{l}8.31 \\
(4.16)^{* * *}\end{array}$ & $\begin{array}{l}6.63 \\
(3.00)^{* * *}\end{array}$ & $\begin{array}{c}0.33 \\
(0.18)\end{array}$ & $\begin{array}{l}6.52 \\
(3.31)^{* * *}\end{array}$ & $\begin{array}{c}2.55 \\
(1.16)\end{array}$ & $\begin{array}{c}3.98 \\
(1.58)\end{array}$ & $\begin{array}{c}2.52 \\
(0.90)\end{array}$ & $\begin{array}{c}4.35 \\
(1.60)\end{array}$ & $\begin{array}{c}-0.13 \\
(-0.03)\end{array}$ & $\begin{array}{l}17.58 \\
(5.05)^{* * *}\end{array}$ & $\begin{array}{l}156.48 \\
(0.000)\end{array}$ \\
\hline \multirow[t]{2}{*}{ Carhart alpha (\% p.a.) } & $\begin{array}{l}15.10 \\
(5.96)^{* * *}\end{array}$ & $\begin{array}{c}7.78 \\
(3.59)^{* * *}\end{array}$ & $\begin{array}{l}5.61 \\
(2.27)^{* *}\end{array}$ & $\begin{array}{c}0.97 \\
(0.50)\end{array}$ & $\begin{array}{l}7.29 \\
(3.52) * * *\end{array}$ & $\begin{array}{c}3.51 \\
(1.41)\end{array}$ & $\begin{array}{l}5.32 \\
(2.01)^{* *}\end{array}$ & $\begin{array}{c}4.84 \\
(1.65)^{*}\end{array}$ & $\begin{array}{c}5.62 \\
(1.93) *\end{array}$ & $\begin{array}{c}0.51 \\
(0.11)\end{array}$ & $\begin{array}{l}14.59 \\
(3.68) * * *\end{array}$ & $\begin{array}{l}104.14 \\
(0.000)\end{array}$ \\
\hline & \multicolumn{12}{|c|}{ Panel C. January 2000-December 2008} \\
\hline CAPM alpha (\% p.a.) & $\begin{array}{l}13.19 \\
(3.61)^{* * *}\end{array}$ & $\begin{array}{l}8.43 \\
(2.53)^{* *}\end{array}$ & $\begin{array}{l}14.98 \\
(4.99) * * *\end{array}$ & $\begin{array}{l}11.04 \\
(2.96) * * *\end{array}$ & $\begin{array}{l}10.69 \\
(2.46)^{* *}\end{array}$ & $\begin{array}{l}12.30 \\
(2.94) * * *\end{array}$ & $\begin{array}{c}7.54 \\
(1.33)\end{array}$ & $\begin{array}{c}4.31 \\
(0.94)\end{array}$ & $\begin{array}{c}5.89 \\
(1.19)\end{array}$ & $\begin{array}{c}2.69 \\
(0.42)\end{array}$ & $\begin{array}{l}10.49 \\
(1.94)^{*}\end{array}$ & $\begin{array}{l}56.70 \\
(0.000)\end{array}$ \\
\hline Fama-French alpha (\% p.a.) & $\begin{array}{l}7.87 \\
(3.39)^{* * *}\end{array}$ & $\begin{array}{c}2.59 \\
(1.34)\end{array}$ & $\begin{array}{l}10.01 \\
(4.40)^{* * *}\end{array}$ & $\begin{array}{l}5.69 \\
(2.06)^{* *}\end{array}$ & $\begin{array}{l}6.46 \\
(1.95)^{*}\end{array}$ & $\begin{array}{l}6.80 \\
(2.06)^{* *}\end{array}$ & $\begin{array}{c}2.14 \\
(0.50)\end{array}$ & $\begin{array}{c}-1.35 \\
(-0.38)\end{array}$ & $\begin{array}{c}0.57 \\
(0.14)\end{array}$ & $\begin{array}{c}-3.39 \\
(-0.69)\end{array}$ & $\begin{array}{l}11.26 \\
(2.26)^{* *}\end{array}$ & $\begin{array}{l}49.03 \\
(0.000)\end{array}$ \\
\hline Carhart alpha (\% p.a.) & $\begin{array}{l}7.34 \\
(3.17)^{* * * *}\end{array}$ & $\begin{array}{c}2.16 \\
(1.08)\end{array}$ & $\begin{array}{l}9.84 \\
(4.15) * * *\end{array}$ & $\begin{array}{l}5.25 \\
(1.88)^{*}\end{array}$ & $\begin{array}{l}5.96 \\
(1.75)^{*}\end{array}$ & $\begin{array}{c}6.39 \\
(1.92)^{*}\end{array}$ & $\begin{array}{c}2.47 \\
(0.55)\end{array}$ & $\begin{array}{c}-1.24 \\
(-0.34)\end{array}$ & $\begin{array}{c}0.65 \\
(0.16)\end{array}$ & $\begin{array}{c}-3.61 \\
(-0.70)\end{array}$ & $\begin{array}{l}10.95 \\
(2.15)^{* *}\end{array}$ & $\begin{array}{l}49.68 \\
(0.000)\end{array}$ \\
\hline
\end{tabular}


TABLE 6

\section{Cross-sectional asset pricing tests}

This table reports the mean of the risk premium coefficients $\lambda_{i}$ estimated from the second stage of the Fama-MacBeth (1973) methodology. This involves monthly cross-sectional regressions of ten value-weighted excess portfolio returns on the corresponding risk factor loadings estimated in the first stage of the procedure (see Section 4.2 for details). These ten portfolios have been constructed by sorting all listed stocks in ascending order according to their Return-toTurnover Rate (RtoTR) ratio. The sample period is February 1991- December 2008. The risk factor loadings used as regressors in the second stage are betas estimated from time-series regressions of excess portfolio returns on several risk factors using rolling windows of 60 monthly observations. However, for early sample periods we start computing betas when there are at least 36 observations. The reported results refer to augmented versions of the Capital Asset Pricing Model, the Fama-French model and the Carhart model (see equation (8)). The additional factor is the price impact (PI) factor that goes long the value-weighted decile portfolio P1 containing the stocks with the lowest RtoTR ratios and goes short the value-weighted decile portfolio P10 containing the stocks with the highest RtoTR ratios. In Panel A we report results from the unrestricted model, while in Panel B we report results from the restricted model where $\lambda_{0}$ is set equal to its zero theoretical value. Fama-MacBeth $t$-statistics are reported in parentheses. We also report in brackets $t$-statistics using Shanken (1992)-corrected standard errors to mitigate the error-in-variables bias. $* * *, * *$ and $*$ indicates that the coefficient is statistically significant at the $1 \%, 5 \%$ and $10 \%$ level, respectively. The pre-last column in Panel A reports the adjusted R-squared coefficient for each model, while the last column reports the increase in the adjusted R-squared coefficient due to the addition of the PI factor to the plain version of the model.

$$
\begin{array}{llllllll}
\lambda_{0} & \lambda_{M K T} & \lambda_{S M B} & \lambda_{H M L} & \lambda_{M O M} & \lambda_{P I} & \text { Adj. } \mathrm{R}^{2} & \Delta \mathrm{R}^{2}
\end{array}
$$

Panel A. Unrestricted Model

\begin{tabular}{|c|c|c|c|c|c|c|c|c|}
\hline 1. CAPM\&PI & $\begin{array}{c}0.99 \\
(1.15) \\
{[1.08]}\end{array}$ & $\begin{array}{l}-1.24 \\
(-1.24) \\
{[-1.18]}\end{array}$ & - & - & - & $\begin{array}{l}0.81 \\
(2.34)^{* *} \\
{[2.30]^{* *}}\end{array}$ & 0.14 & 0.06 \\
\hline 2. Fama-French\&PI & $\begin{array}{c}2.02 \\
(1.63) \\
{[1.33]}\end{array}$ & $\begin{array}{c}-2.41 \\
(-1.70)^{*} \\
{[-1.40]}\end{array}$ & $\begin{array}{c}0.21 \\
(1.24) \\
{[1.06]}\end{array}$ & $\begin{array}{c}-0.32 \\
(-0.44) \\
{[-0.36]}\end{array}$ & - & $\begin{array}{c}0.97 \\
(2.96)^{* * *} \\
{[2.82]^{* * *}}\end{array}$ & 0.20 & 0.05 \\
\hline 3. Carhart\&PI & $\begin{array}{c}1.74 \\
(1.19) \\
{[0.96]}\end{array}$ & $\begin{array}{l}-2.16 \\
(-1.32) \\
{[-1.07]}\end{array}$ & $\begin{array}{c}0.29 \\
(1.02) \\
{[0.84]}\end{array}$ & $\begin{array}{c}-0.59 \\
(-0.76) \\
{[-0.62]}\end{array}$ & $\begin{array}{c}0.25 \\
(0.68) \\
{[0.56]}\end{array}$ & $\begin{array}{c}0.94 \\
(2.94)^{* * *} \\
{[2.82]^{* * *}}\end{array}$ & 0.25 & 0.05 \\
\hline \multicolumn{9}{|c|}{ Panel B. Restricted model: $\lambda_{0}$ is set to equal zero } \\
\hline 4. CAPM\&PI & set to 0 & $\begin{array}{c}-0.19 \\
(-0.62) \\
{[-0.62]}\end{array}$ & - & - & - & $\begin{array}{l}0.81 \\
(2.25)^{* *} \\
{[2.23]^{* *}}\end{array}$ & - & - \\
\hline 5. Fama-French\&PI & set to 0 & $\begin{array}{c}-0.21 \\
(-0.68) \\
{[-0.67]}\end{array}$ & $\begin{array}{c}0.08 \\
(0.57) \\
{[0.55]}\end{array}$ & $\begin{array}{c}0.29 \\
(0.50) \\
{[0.48]}\end{array}$ & - & $\begin{array}{c}0.93 \\
(2.79)^{* * *} \\
{[2.75]^{* * *}}\end{array}$ & - & - \\
\hline 6. Carhart\&PI & set to 0 & $\begin{array}{l}-0.19 \\
(-0.62) \\
{[-0.61]}\end{array}$ & $\begin{array}{c}-0.13 \\
(-0.75) \\
{[-0.68]}\end{array}$ & $\begin{array}{c}0.18 \\
(0.32) \\
{[0.28]}\end{array}$ & $\begin{array}{l}0.63 \\
(2.22)^{* *} \\
{[1.97]^{* *}}\end{array}$ & $\begin{array}{c}0.92 \\
(2.83)^{* * *} \\
{[2.74]^{* * *}}\end{array}$ & - & - \\
\hline
\end{tabular}




\section{TABLE 7}

\section{Momentum and size alphas from PI-augmented asset pricing models}

This table reports the abnormal performance of momentum (Panel A) and size (Panel B) strategies derived from the Capital Asset Pricing Model, the Fama-French and the Carhart model as well as their augmented versions, where the additional price impact PI factor. This PI factor is constructed by going long the valueweighted decile portfolio P1 containing the stocks with the lowest Return-to-Turnover Rate (RtoTR) ratios and goes short the value-weighted decile portfolio P10 containing the stocks with the highest RtoTR ratios. To calculate the returns of the momentum strategy in month $t$, we sort all listed stocks at month $t-1$ according to their returns from month $t-13$ to month $t-2$ and assign them to ten portfolios. The momentum strategy goes long the value-weighted decile portfolio P10 containing the stocks with the highest prior returns (winners) and goes short the value-weighted decile portfolio P1 containing the stocks with the lowest prior returns (losers). To calculate the returns of the size strategy in month $t$, we sort all listed stocks at month $t$ - 1 according to their market capitalization and assign them to ten portfolios. The size strategy goes long the value-weighted decile portfolio P1 containing the stocks with the smallest market capitalization and goes short the value-weighted decile portfolio P10 containing the stocks with the highest market capitalization. $t$ statistics for the alpha coefficients are reported in parentheses. $* * *, * *$ and $*$ indicates that the alpha coefficient is statistically significant at the $1 \%, 5 \%$ and $10 \%$ level, respectively.

\begin{tabular}{|c|c|c|c|}
\hline & $\begin{array}{l}\text { February 1991- } \\
\text { December } 2008\end{array}$ & $\begin{array}{l}\text { February 1991- } \\
\text { December } 1999\end{array}$ & $\begin{array}{c}\text { January 2000- } \\
\text { December } 2008\end{array}$ \\
\hline \multicolumn{4}{|c|}{ Panel A. Momentum alphas } \\
\hline 1. CAPM alpha & $\begin{array}{l}22.78 \\
(2.78)^{* * *}\end{array}$ & $\begin{array}{l}29.35 \\
(2.73)^{* * * *}\end{array}$ & $\begin{array}{l}11.57 \\
(1.08)\end{array}$ \\
\hline 2. CAPM\&PI alpha & $\begin{array}{l}16.71 \\
(2.10)^{* *}\end{array}$ & $\begin{array}{l}16.88 \\
(1.87)^{*}\end{array}$ & $\begin{array}{c}9.57 \\
(0.83)\end{array}$ \\
\hline 3. Fama-French alpha & $\begin{array}{l}25.12 \\
(3.73)^{* * *}\end{array}$ & $\begin{array}{l}27.35 \\
(3.57)^{* * *}\end{array}$ & $\begin{array}{l}17.43 \\
(1.68)^{*}\end{array}$ \\
\hline 4. Fama-French\&PI alpha & $\begin{array}{l}19.81 \\
(2.96)^{* *}\end{array}$ & $\begin{array}{l}18.99 \\
(2.71)^{* * *}\end{array}$ & $\begin{array}{l}14.34 \\
(1.25)\end{array}$ \\
\hline 5. Carhart alpha & $\begin{array}{l}9.44 \\
(1.97)^{* *}\end{array}$ & $\begin{array}{l}12.93 \\
(2.30)^{* *}\end{array}$ & $\begin{array}{c}5.80 \\
(0.77)\end{array}$ \\
\hline 6. Carhart\&PI alpha & $\begin{array}{c}4.67 \\
(0.98) \\
\end{array}$ & $\begin{array}{c}7.84 \\
(1.32) \\
\end{array}$ & $\begin{array}{c}1.29 \\
(0.17) \\
\end{array}$ \\
\hline \multicolumn{4}{|c|}{ Panel B. Size alphas } \\
\hline 7. CAPM alpha & $\begin{array}{l}17.56 \\
(2.69)^{* * *}\end{array}$ & $\begin{array}{l}13.40 \\
(1.51)\end{array}$ & $\begin{array}{l}22.44 \\
(2.90)^{* * * *}\end{array}$ \\
\hline 8. CAPM\&PI alpha & $\begin{array}{l}27.02 \\
(4.37) * * *\end{array}$ & $\begin{array}{l}20.68 \\
(2.41)^{* * *}\end{array}$ & $\begin{array}{l}32.66 \\
(4.63)^{* * * *}\end{array}$ \\
\hline 9. Fama-French alpha & $\begin{array}{l}14.66 \\
(2.76)^{* * *}\end{array}$ & $\begin{array}{l}14.78 \\
(2.07)^{* *}\end{array}$ & $\begin{array}{l}15.64 \\
(2.53)^{* *}\end{array}$ \\
\hline 10.Fama-French\&PI alpha & $\begin{array}{l}21.69 \\
(4.19)^{* * *}\end{array}$ & $\begin{array}{l}16.16 \\
(2.39)^{* *}\end{array}$ & $\begin{array}{l}25.99 \\
(4.49)^{* * *}\end{array}$ \\
\hline 11.Carhart alpha & $\begin{array}{l}11.85 \\
(2.55)^{* *}\end{array}$ & $\begin{array}{c}9.40 \\
(1.66)\end{array}$ & $\begin{array}{l}14.20 \\
(2.31)^{* *}\end{array}$ \\
\hline 12.Carhart\&PI alpha & $\begin{array}{l}18.86 \\
(3.93) * * *\end{array}$ & $\begin{array}{l}11.47 \\
(1.90)^{*}\end{array}$ & $\begin{array}{l}24.65 \\
(4.09)^{* * *}\end{array}$ \\
\hline
\end{tabular}




\section{TABLE 8}

\section{Percentage weights in the ex post tangency portfolio}

Each column in this table reports the percentage weights of the available assets in the ex post tangency portfolio as well as the ex post monthly Sharpe ratio of the corresponding tangency portfolio. The asset universe in each case is consisted of various subsets of five traded factors: excess market returns (MKT), size (SMB), value (HML), momentum (MOM) and the price impact (PI) factor that goes long the valueweighted decile portfolio P1 containing the stocks with the lowest Return-to-Turnover Rate (RtoTR) ratios and goes short the value-weighted decile portfolio P10 containing the stocks with the highest RtoTR ratios. Panel A contains the results for the period February 1991- December 2008, while Panel B presents the corresponding results for the subperiod February 1991- December 2006.

\begin{tabular}{lccccccc}
\hline \hline \multicolumn{7}{c}{ Panel A. February 1991 - December 2008} \\
\hline MKT & 100 & -22.85 & -21.95 & -2.89 & 2.74 & -1.67 & -0.21 \\
SMB & $\ldots$ & 122.85 & 113.02 & 31.72 & $\ldots$ & 68.93 & 42.76 \\
HML & $\ldots$ & $\ldots$ & 8.94 & 11.99 & $\ldots$ & -0.38 & 5.76 \\
MOM & $\ldots$ & $\ldots$ & $\ldots$ & 59.18 & $\ldots$ & $\ldots$ & 34.14 \\
PI & $\ldots$ & $\ldots$ & $\ldots$ & $\ldots$ & 97.26 & 33.11 & 17.54 \\
Sharpe Ratio & -0.036 & 0.083 & 0.084 & 0.240 & 0.266 & 0.333 & 0.398 \\
\hline \hline \multicolumn{7}{c}{ Panel B. February 1991- December 2006 } \\
MKT & 100 & 1.47 & -0.04 & 1.22 & 19.76 & 2.89 & 2.52 \\
SMB & $\ldots$ & 98.53 & 89.63 & 35.53 & $\ldots$ & 68.44 & 47.97 \\
HML & $\ldots$ & $\ldots$ & 10.41 & 12.13 & $\ldots$ & 2.00 & 5.79 \\
MOM & $\ldots$ & $\ldots$ & $\ldots$ & 51.13 & $\ldots$ & $\ldots$ & 26.27 \\
PI & $\ldots$ & $\ldots$ & $\ldots$ & $\ldots$ & 80.24 & 26.67 & 17.45 \\
Sharpe Ratio & 0.023 & 0.123 & 0.128 & 0.251 & 0.268 & 0.381 & 0.422 \\
\hline \hline
\end{tabular}


TABLE 9

Correlations of traded factors' returns

This table presents the pairwise correlation coefficients of monthly returns for five traded factors: excess market returns (MKT), size (SMB), value (HML), momentum (MOM) and the price impact (PI) factor that goes long the value-weighted decile portfolio P1 containing the stocks with the lowest Return-to-Turnover Rate (RtoTR) ratios and goes short the value-weighted decile portfolio P10 containing the stocks with the highest RtoTR ratios. Panel A contains the correlation matrix for the period February 1991- December 2008, while Panel B refers to the subperiod February 1991December 2006.

\begin{tabular}{|c|c|c|c|c|c|}
\hline \multicolumn{6}{|c|}{ Panel A. February 1991- December 2008} \\
\hline & \multicolumn{5}{|c|}{ Correlation Matrix } \\
\hline MKT & 1.00 & & & & \\
\hline SMB & 0.19 & 1.00 & & & \\
\hline HML & 0.16 & 0.03 & 1.00 & & \\
\hline MOM & -0.15 & -0.18 & -0.37 & 1.00 & \\
\hline PI & -0.16 & -0.43 & 0.02 & 0.09 & 1.00 \\
\hline \multicolumn{6}{|c|}{ Panel B. February 1991- December 2006} \\
\hline \multicolumn{6}{|c|}{ Correlation Matrix } \\
\hline MKT & 1.00 & & & & \\
\hline SMB & 0.13 & 1.00 & & & \\
\hline HML & 0.19 & 0.06 & 1.00 & & \\
\hline MOM & -0.15 & -0.11 & -0.37 & 1.00 & \\
\hline PI & -0.16 & -0.46 & -0.02 & 0.13 & 1.00 \\
\hline
\end{tabular}




\section{FIGURE 1}

\section{Goodness of fit of the PI-adjusted CAPM}

This Figure shows the goodness of fit of the PI-adjusted CAPM, utilizing the ten value-weighted RtoTRsorted portfolios as test portfolios. In particular, it plots the annualized actual mean excess returns of these portfolios for the period February 1991- December 2008 versus the corresponding returns predicted by the PI-adjusted CAPM, given in equation (10). The estimation of the portfolios' returns sensitivities to the traded factors and their premia has been performed via a GMM estimator as explained in Section 4.2.

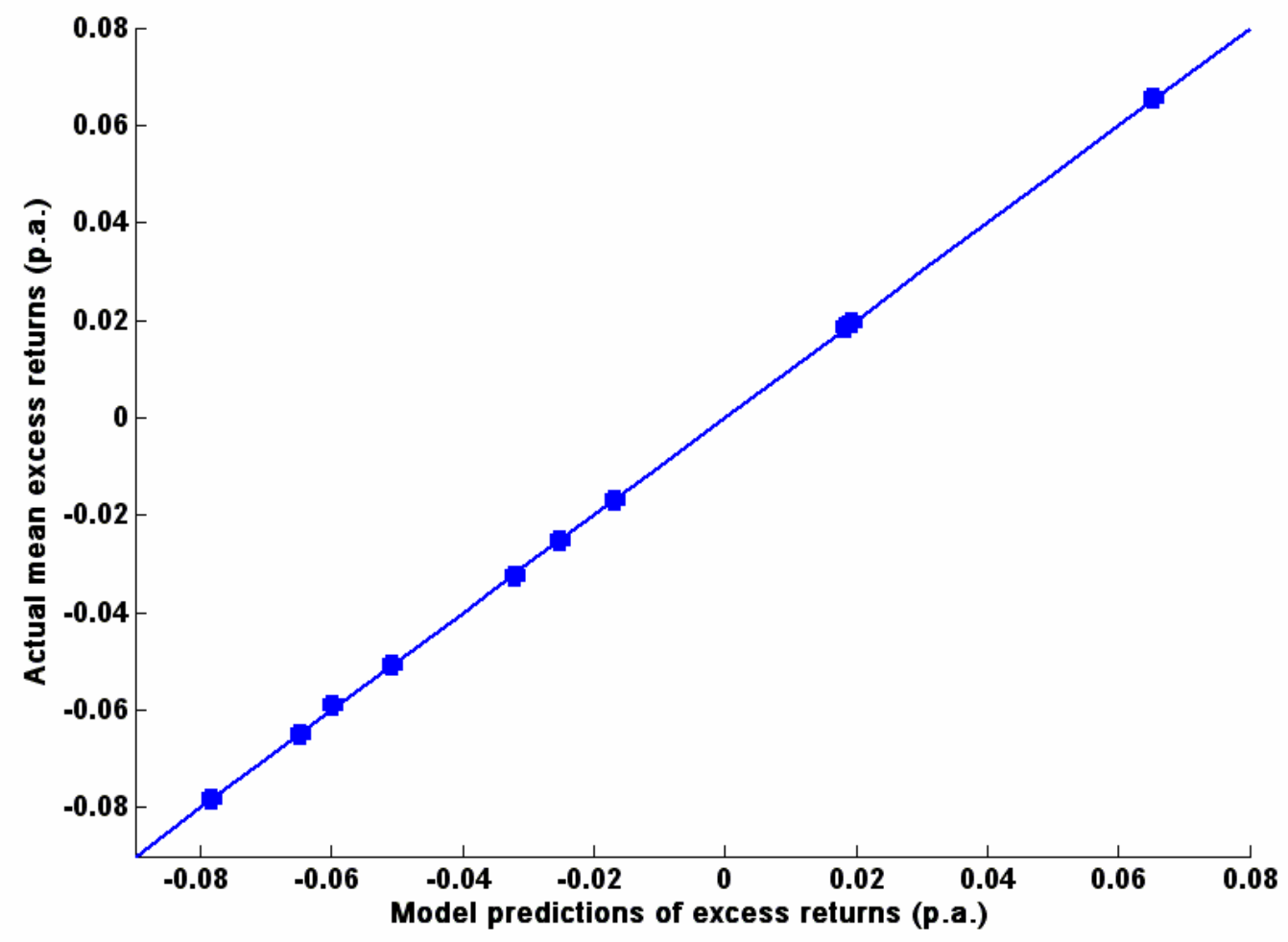

